\title{
Análisis descriptivo del comercio internacional entre Colombia y Estados Unidos a partir del Tratado de Libre Comercio
}

\author{
Dayana Camila Beltrán-Bejarano ${ }^{1}$ \\ Universidad Ean \\ dbeltran3898@universidadean.edu.co \\ Laura Cristina Bohórquez-Montes ${ }^{2}$ \\ Universidad Ean \\ lbohorqu1914@universidadean.edu.co
}

DOI: https://doi.org/10.21158/23227230.v9.n0.2019.2873

Cómo citar este artículo: Beltrán-Bejarano, D. C.; Bohórquez-Montes, L. C. (2019). Análisis descriptivo del comercio internacional entre Colombia y Estados Unidos a partir del Tratado de Libre Comercio. Revista Ploutos, 9, (Páginas). DOI: https://doi.org/10.21158/23227230.v9.n0.2019.2873

Fecha de recepción: 08 de junio de 2020

Fecha de aprobación: 21 de septiembre de 2020

\section{Resumen}

El objetivo de este trabajo de investigación es realizar un análisis descriptivo del tratado de libre comercio (TLC) con Estados Unidos, el cual entró en vigor en el 2012, a partir del comportamiento de los flujos comerciales según su posición arancelaria, sector económico y departamento de origen y destino, entre el 2012 y el 2019. Adicionalmente, se describe el comportamiento comercial entre los principales departamentos identificados y Estados Unidos durante los mismos años. Desde la entrada en vigencia del TLC con Estados Unidos -2012-2019no se evidencia un cambio representativo de los principales productos comercializados entre los dos países. Las exportaciones han disminuido, posiblemente por la reducción del precio del petróleo en los últimos años, el cual se destaca como el rubro exportador principal, aunque con menor participación que en el 2012, mientras que los sectores manufacturero y agrícola reflejan un aumento en sus exportaciones. En cuanto a las importaciones, estas se caracterizaron por ser manufacturas. Los departamentos más representativos, según el valor de las exportaciones e importaciones con Estados Unidos, son Antioquia, Atlántico, Bogotá, Bolívar, Cundinamarca y Valle del Cauca.

Palabras clave: comercio internacional; comercio bilateral; tratado de libre comercio; comportamiento comercial; exportaciones colombianas; crecimiento económico.

\footnotetext{
${ }^{1}$ Economista - Universidad Ean. Integrante del semillero DOMUS. ORCID: https://orcid.org/0000-0002-8427-0256

2 Economista - Universidad Ean. Integrante del semillero DOMUS. ORCID: https://orcid.org/0000-0003-1593-3332
} 


\title{
Descriptive analysis of the international trade between Colombia and the United States based on the Free Trade Agreement (FTA)
}

\begin{abstract}
The aim of this research is to perform a descriptive analysis of the Free Trade Agreement (FTA) with the United States, which came into effect in 2012, based on the behavior of trade flows according to their tariff position, economic sector, and department of origin and destination, between 2012 and 2019. Additionally, we describe the trade behavior between the main departments identified and the United States during the same years. Ever since the FTA with the United States came into existence (2012-2019) there has been no evidence of a representative change in the main products traded between the two countries. Exports have decreased, possibly due to the reduction in the price of oil in recent years, which stands out as the main export item, although with less participation than in 2012, while the manufacturing and agricultural sectors reflect an increase in their exports. As for imports, these were characterized by being manufactured goods. The most representative departments, according to the value of exports and imports with the United States, are Antioquia, Atlántico, Bogotá, Bolívar, Cundinamarca, and Valle del Cauca.
\end{abstract}

Keywords: international trade; bilateral trade; free trade agreement; trade behavior; Colombian exports; economic growth.

\section{Análise descritiva do comércio internacional entre a Colômbia \\ e os Estados Unidos com base no Tratado de Livre Comércio}

\section{Resumo}

O objetivo deste trabalho de pesquisa é realizar uma análise descritiva do Tratado de Livre Comércio (TLC) com os Estados Unidos, que entrou em vigor em 2012, com base no comportamento dos fluxos comerciais segundo sua posição tarifária, setor econômico e estado de origem e destino, entre 2012 e 2019. Adicionalmente, descreve-se o comportamento comercial entre os principais departamentos identificados e os Estados Unidos durante os mesmos anos. Desde a entrada em vigor do TLC com os Estados Unidos - 2012-2019 - não há evidências de mudança representativa nos principais produtos comercializados entre os dois países. As exportações diminuíram, possivelmente devido à redução do preço do petróleo nos últimos anos, que se destaca como principal item de exportação, embora com menor participação comparado ao ano de 2012, enquanto os setores manufatureiro e agrícola refletem um aumento nas suas exportações. Sobre as importações, caracterizaram-se por serem manufaturas. Os departamentos mais representativos, segundo o valor das exportações e importações com os Estados Unidos, são Antioquia, Atlântico, Bogotá, Bolívar, Cundinamarca e Valle del Cauca.

Palavras-chave: comércio internacional, comércio bilateral, tratado de Livre Comércio, comportamento comercial, exportações colombianas, crescimento econômico. 


\section{Analyse descriptive du commerce international entre la Colombie et les États-Unis sur la base de l'Accord de libre-échange}

\section{Résumé}

Cette étude réalise une analyse descriptive de l'accord de libre-échange (ALE) colombo-américain, sur la période 2012-2019 en se basant sur le comportement des flux commerciaux en fonction de leur position tarifaire, du secteur économique et de la région d'origine comme de destination. Nous décrirons par ailleurs le comportement commercial des principaux départements identifiés avec les États-Unis sur la période étudiée. Depuis l'entrée en vigueur de l'ALE avec les États-Unis en 2012, aucun changement fondamental des principaux produits échangés entre les deux pays n'a été constaté. Les exportations pétrolières ont diminué sur la période, sans doute en raison de la baisse du cours du baril ces dernières années, mais restent le principal poste d'exportation, tandis que les secteurs manufacturier et agricole montrent une hausse des volumes exportés. Les importations restent pour leur part principalement des produits manufacturés. Les départements colombiens les plus représentatifs du commerce bilatéral sont Antioquia, Atlántico, Bogotá, Bolívar, Cundinamarca et Valle del Cauca.

Mots-clés: commerce international; échange bilatéral; traité de libre-échange; comportement commercial; exportations colombiennes; croissance économique.

\section{Introducción}

Los TLC son acuerdos realizados entre dos o más países en busca de ventajas económicas mutuas, tales como reforzar la estabilidad macroeconómica, diversificar el mercado, reforzar la seguridad jurídica y facilitar el comercio en todos sus términos. Según la teoría económica, un acuerdo comercial permite que una economía se especialice en la producción de bienes y servicios, por lo cual, al poseer una ventaja comparativa con respecto a las demás, aumenta su competitividad.

En Colombia, el libre comercio ha permitido ampliar el mercado y fomentar la inversión extranjera, potencializando, principalmente, su sector primario. Sin embargo, la especialización en este sector hace que la economía sea susceptible a cambios en los precios internacionales de las materias primas, tal como se evidenció en Colombia durante el 2014 con la caída del precio del petróleo. Adicionalmente, la diversificación de la economía define importantes aspectos tales como el empleo, la estabilidad macroeconómica y el desarrollo del capital humano y físico. 
Considerando lo anterior, es relevante conocer el sector importador y exportador de la economía colombiana con Estados Unidos como su principal socio comercial, con el fin de identificar avances en la diversificación de las exportaciones y, en general, conocer el comportamiento comercial a partir del TLC implementado. Además, esta investigación servirá de insumo para futuros trabajos de evaluación de impacto, análisis descriptivos y estadísticos, entre otros.

En economía internacional (Krugman y Obstfeld, 2006), la teoría económica respalda que en el comercio internacional existen ganancias del comercio: si dos países realizan intercambios de bienes y servicios, se produce un beneficio mutuo. El comercio internacional produce ventajas compartidas, incluso si un país es más eficiente en la producción de todos los bienes y el país menos eficiente solo puede competir con salarios inferiores. Igualmente, permite que un país exporte bienes cuya producción es intensiva en los factores productivos que son abundantes en el país e importe aquellos cuya producción es intensiva en los factores productivos que son escasos.

Los estudios realizados previa a la implementación del TLC con Estados Unidos demuestran que su alcance depende de la disminución de barreras no arancelarias, en la medida en que beneficiaría el crecimiento económico en Colombia, favoreciendo a los más pobres y generando un efecto progresivo en la distribución del ingreso (Martín y Ramírez, 2004). Estas barreras no arancelarias se representan en restricciones cuantitativas, requerimientos de contenido, medidas de frontera y normas fitosanitarias, entre otras.

Según Casas, León y Meléndez (2005), la implementación de un acuerdo comercial tendrá un efecto en la integración económica regional del país, producto de la especialización de la producción de este con respecto a la ventaja comparativa que tengan sobre los demás países miembros del acuerdo, lo que conlleva a que las regiones que concentran la actividad productiva se pueden expandir o contraer. 
En el artículo «El TLC de Colombia con Estados Unidos y sus implicaciones en los departamentos colombianos» (Moncayo-Jiménez, 2006) se expone la vulnerabilidad de la economía departamental ante un eventual aumento de las importaciones de los bienes competitivos, los cuales cuentan con un comercio intraindustrial y tienen oportunidades de exportación - materias primas agropecuarias y bienes de consumo-. Además, muestra que existe el riesgo de la agudización de los problemas estructurales en la economía, tales como el bajo crecimiento, la involución del cambio sectorial, el desempleo y la mala distribución del ingreso.

Ladino y Madrid (2015) explican la influencia que posee Estados unidos frente a la economía colombiana al ser el principal socio comercial para el país, en términos de exportaciones; además evalúan el impacto que ha generado el TLC entre Colombia y Estados Unidos para la economía nacional, con un énfasis en las exportaciones de Colombia hacia los estados de Connecticut, Colorado, Delaware, Dakota del Sur y Florida, así como las posibles oportunidades comerciales.

Este artículo consta de cinco secciones: la primera es esta introducción; la segunda sección explica la metodología implementada en la investigación; la tercera sección es de resultados y se compone de dos partes: a) una descripción del comercio entre Colombia y Estados Unidos, según el valor de exportaciones e importaciones totales, por departamento y por sector económico, con énfasis en el periodo de tiempo de la implementación del TLC -2012-2019-; y b) una descripción de las principales posiciones arancelarias de los departamentos más representativos del comercio entre Colombia y Estados Unidos entre el 2012 y el 20193. Por último, la cuarta sección presenta conclusiones y recomendaciones para estudios posteriores.

\footnotetext{
${ }^{3}$ Los departamentos se definen según su participación en valor en las exportaciones e importaciones y son: Antioquia, Atlántico, Bogotá D. C., Bolívar, Cundinamarca y Valle del Cauca.
} 


\section{Metodología}

La principal fuente de información utilizada en esta investigación son los microdatos de comercio internacional publicados por el Departamento Administrativo Nacional de Estadística (DANE). Esta información recoge datos individuales de exportaciones e importaciones y las variables que se tuvieron en cuenta son: el lugar de salida y origen de las exportaciones, el lugar de destino de las importaciones, el valor USD FOB — free on boardde las exportaciones y el valor USD CIF — cost, insrance and freight - de las importaciones, y la posición arancelaria o producto. El tratamiento de los datos se realizó con el software de análisis de datos $\mathrm{R}$, en razón a su gran volumen de información.

Los criterios para definir las variables utilizadas son que el sitio de origen refleja el lugar de producción del bien, a diferencia del lugar de procedencia; el valor en dólares no incluye el efecto de la tasa de cambio; el valor CIF y FOB son comparables porque no incluyen el costo de seguro y transporte por parte de Colombia; y las posiciones arancelarias pueden relacionarse con el CIIU (Clasificación Internacional Industrial Uniforme) y representarse en las grandes ramas de la actividad en Colombia.

La investigación utiliza una metodología descriptiva, al ser un primer acercamiento a los microdatos de comercio internacional del DANE, y parte de los aspectos generales a específicos a fin de caracterizar el comercio entre Colombia y Estados Unidos. Además, el método deductivo permite desarrollar conclusiones de los resultados bajo los principios teóricos de la economía internacional, fuentes externas que han analizado el comercio internacional entre Colombia y Estados Unidos, así como una contextualización del TLC que se presenta en la primera parte de los resultados. 


\section{Resultados}

\subsection{Análisis del comercio exterior entre Colombia y Estados Unidos}

A partir de la década de los noventa una serie de reformas, en la línea de la liberalización económica y el Consenso de Washington, priorizaron la internacionalización de la economía y fomentaron el comercio exterior a través de tratados de libre comercio con el fin de potenciar la economía y aumentar la productividad y la competitividad del país.

Al dejar de lado el anterior modelo de industrialización por sustitución de importaciones, se implementó la libre importación a más del 90 \% de los bienes y servicios comerciados, se simplificó la estructura arancelaria y se redujeron los aranceles. Estas medidas se empezaron a reflejar en la mayor importancia del comercio exterior en la economía y se consolidó una caracterización de las exportaciones e importaciones en Colombia. Las importaciones fueron, principalmente, de bienes industriales y algunos agropecuarios, así como de servicios, mientras que el sector exportador se especializó en el sector de minería e hidrocarburos (Bonilla-González, 2011).

Para inicios del siglo XXI, el modelo de desarrollo económico se asemejó al de un país minero-exportador, en el cual predominó el sector primario, mientras que el industrial perdió competitividad. Este modelo se basó en una estrategia de concesiones y contratos de exploración y explotación del subsuelo, sector que contribuyó al aumento de la inversión extranjera y al deterioro del mercado laboral, por ser actividades intensivas en capital y no en trabajo (Bonilla-González, 2011).

Los primeros acuerdos comerciales entre Colombia y Estados Unidos surgieron a partir de la Ley de Preferencias Arancelarias Andinas -ATPA, por sus siglas en inglés- y la Ley de Preferencias Arancelarias Andinas y de Erradicación de Drogas -ATPDEA, por sus siglas en inglés- expedidas en 1991 y en el 2002, respectivamente. Ambas promulgadas con el fin de crear alternativas de empleo que sustituyeran la producción y el tráfico ilícito de drogas mediante la diversificación y el aumento del comercio entre los países andinos y 
Estados Unidos. El ATPA eliminó las barreras arancelarias de cerca de 5600 productos y a partir de la entrada en vigor del ATPDEA se ampliaron las preferencias, así como se incluyeron 700 productos más (Procolombia, s. f.).

El Acuerdo de promoción comercial entre la República de Colombia y los Estados Unidos de América, estipulado en el Decreto 993 del 15 de mayo de 2012, surge de la necesidad de encontrar nuevos mercados en el exterior mediante la creación de la posibilidad de que los empresarios realicen inversiones a largo plazo, aumenten su capacidad productiva y cuenten con una estabilidad en el tiempo (Ministerio de Comercio, Industria y Turismo, s. f.).

Según el informe sobre los acuerdos comerciales vigentes de Colombia del 2018, realizado por el Ministerio de Comercio, Industria y Turismo (Mincit), la implementación del TLC con Estados Unidos amplió la cobertura de productos con preferencias arancelarias, pasando de cerca de 5670 productos con el ATPDEA a más de 10634 con el TLC, los cuales tienen $0 \%$ de arancel. Para la fecha del informe, se exportaron 286 nuevos productos que antes del acuerdo no se exportaban.

La participación promedio en las exportaciones de Colombia por destino durante el periodo 2012-2019 (Figura 1) muestra a Estados Unidos como su principal destino, con una participación del 29,8 \% del total de las exportaciones. Los países que le siguen son China 7,9 \%—, Panamá -6,1 \%—, España —4,0 \%—, Ecuador —3,8 \%—, Países Bajos -3,7 \%— y Brasil -3,1\%-. La importancia de analizar los flujos comerciales entre Estados Unidos y Colombia se confirma al observar que Estados Unidos cuenta con una diferencia importante en la participación de las exportaciones colombianas con respecto a los socios comerciales que le siguen en participación. 
Figura 1. Participación en las exportaciones de Colombia por destino —2012-2019—

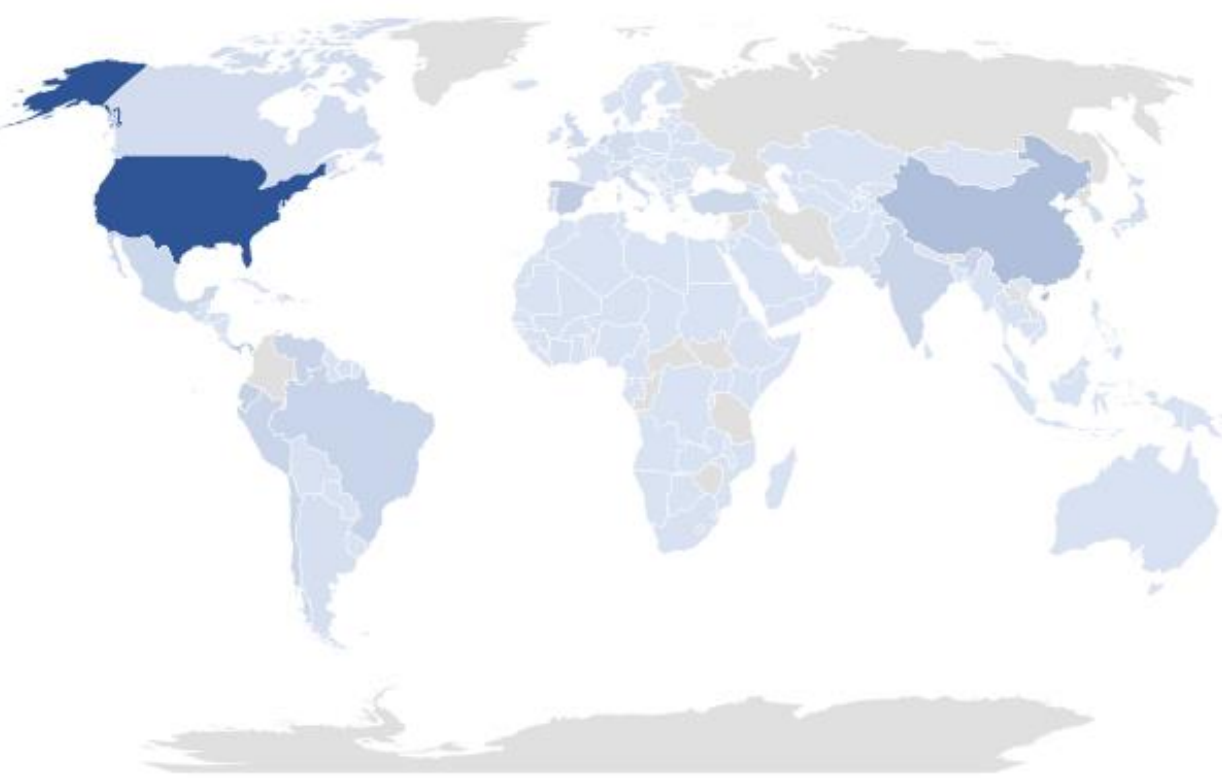

Con teconologia de Bing

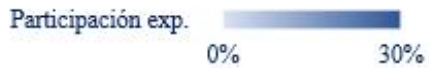

Fuente. Elaboración propia con datos del DANE.

$\mathrm{Al}$ analizar el comercio exterior entre Colombia y Estados Unidos (Figura 2), este ha presentado un aumento significativo entre el 2000 y el 2019, con un incremento del $84 \%$ al pasar de 67 millones de tn —toneladas-a 123 millones de th en el 2019. Por su parte, las importaciones crecieron un $192 \%$, pasando de 13 millones de th en el 2000 a 38 millones de th en el 2019. A partir de la entrada en vigencia del TLC - 2012 - no se observa un cambio significativo en la tendencia de las exportaciones y las importaciones por valor en dólares y toneladas. 
Figura 2. Flujos comerciales entre Colombia y Estados Unidos — 2000-2019—

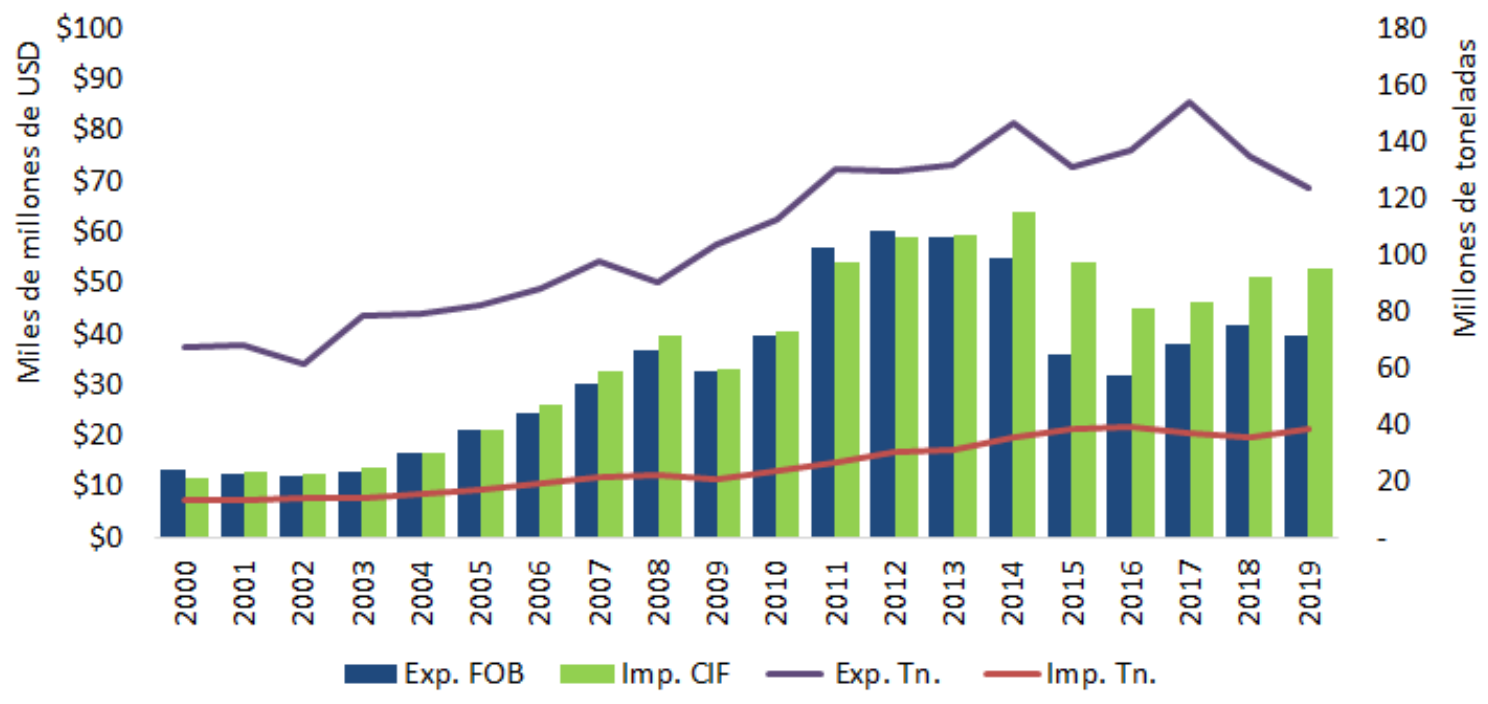

Fuente. Elaboración propia con datos del DANE.

En el informe sobre acuerdos comerciales vigentes de Colombia (Ministerio de Comercio, Industria y Turismo, 2018) se le atribuye a la caída de los precios del petróleo la razón de la disminución en las exportaciones durante el periodo 2012-2017. Adicionalmente, la balanza comercial de Colombia es deficitaria desde el 2014, y la representación de las exportaciones hacia Estados Unidos sobre el total de exportaciones de Colombia disminuyó en un 7,1 \% y aumentó en un 1,2 \% en las importaciones.

\subsubsection{Exportaciones de Colombia hacia Estados Unidos — 2012 y 2019—.}

El lugar de salida de las exportaciones de Colombia hacia Estados Unidos en el 2012 y el 2019 (Tabla 1) más importante fue Coveñas, con una representación del 15,4 \% y un 3,8 \% del total de las exportaciones, respectivamente. El municipio de Coveñas - Sucreestá ubicado en la Costa Caribe, en el Golfo de Morrosquillo; el Terminal Marítimo de Coveñas es el principal puerto de movimiento de hidrocarburos en Colombia, principalmente de la empresa colombiana Ecopetrol (Ecopetrol, 2014). 
Otros lugares de salida representativos durante el 2012 fueron Medellín, Cartagena y Bogotá, tres ciudades principales en las que se exportaron el 12,8 \%, 7,4 \% y 5,4\%, en su orden, del total de las exportaciones -21,833 millones USD FOB —. Por su parte, en el 2019 los principales lugares de salida fueron Mamonal —11,9\%—, Bogotá -11,1\%—, Cartagena -10,3 \%-, Medellín -6,4 \%- y Buenaventura -6,4\%-, representando, en su totalidad, junto con Coveñas, el 89,8 \% del total de las exportaciones durante este año -10 674 millones USD FOB - Se evidencia que las seis principales ciudades y puertos marítimos del país concentran la mayoría de las exportaciones durante el 2019.

Tabla 1. Lugar de salida de las exportaciones de Colombia hacia Estados Unidos — 2012 y 2019—

\begin{tabular}{|l|c|c|c|c|}
\hline \multirow{2}{*}{ Lugar de Salida } & \multicolumn{2}{|c|}{ Millones USD } & \multicolumn{2}{c|}{$\begin{array}{c}\text { Participación en las } \\
\text { exportaciones }\end{array}$} \\
\cline { 2 - 5 } & $\mathbf{2 0 1 2}$ & $\mathbf{2 0 1 9}$ & $\mathbf{2 0 1 2}$ & $\mathbf{2 0 1 9}$ \\
\hline Coveñas & 3,357 & 4,554 & $15.4 \%$ & $43.8 \%$ \\
Cartagena & 1,609 & 1,066 & $7.4 \%$ & $10.3 \%$ \\
Bogotá & 1,169 & 1,157 & $5.4 \%$ & $11.1 \%$ \\
Mamonal & 241 & 1,235 & $1.1 \%$ & $11.9 \%$ \\
Medellín & 2,791 & 664 & $12.8 \%$ & $6.4 \%$ \\
Buenaventura & 532 & 662 & $2.4 \%$ & $6.4 \%$ \\
Barranquilla & 273 & 441 & $1.3 \%$ & $4.2 \%$ \\
Santa Marta & 462 & 303 & $2.1 \%$ & $2.9 \%$ \\
Tumaco & 0 & 185 & $0.0 \%$ & $1.8 \%$ \\
Cali & 277 & 101 & $1.3 \%$ & $1.0 \%$ \\
Uraba & 174 & 0 & $0.8 \%$ & $0.0 \%$ \\
Riohacha & 157 & 16 & $0.7 \%$ & $0.2 \%$ \\
Armenia & 0 & 1 & $0.0 \%$ & $0.0 \%$ \\
Pereira & 1 & 10 & $0.0 \%$ & $0.1 \%$ \\
Bucaramanga & 0 & 1 & $0.0 \%$ & $0.0 \%$ \\
San Andrés & 3 & 0 & $0.0 \%$ & $0.0 \%$ \\
Cúcuta & 65 & 0 & $0.3 \%$ & $0.0 \%$ \\
\hline
\end{tabular}

Nota: La suma de las exportaciones por lugar de salida no corresponde al total de las exportaciones del año correspondiente debido a algunos datos en blanco de la base de microdatos.

Fuente. Elaboración propia con datos del DANE. 
La tabla 2 muestra la distribución de las exportaciones por departamento de origen en el 2012 y el 2019; para los dos años existe una importante concentración en el departamento de origen que el DANE denomina como «Petróleo y derivados», con una participación de 54,0 \% para el 2012 y de 43,1 \% para el 2019, pasando de 11,966 a 4,968 -millones USD FOB —, posiblemente producto de la caída del precio del petróleo durante ese periodo.

Los lugares de origen que le siguen en representación a «Petróleo y derivados» son Antioquia - 15,2\%-, Bogotá - 5,0 \%- y Casanare - 4,5 \% - en el 2012, y Antioquia 11,2\%-, Bogotá $-7,0 \%$ - y Cundinamarca $-5,5 \%$ - en el 2019. Si se suma la participación en las exportaciones de los principales diez departamentos en cada año, se pasó de una concentración del 38,3 \% al 45,9\%.

Tabla 2. Departamento de origen de las exportaciones de Colombia hacia Estados Unidos - 2012 y $2019-$

\begin{tabular}{|c|c|c|c|c|}
\hline \multirow[t]{2}{*}{ Departamento de Origen } & \multicolumn{2}{|c|}{$\begin{array}{c}\text { Millones USD } \\
\text { FOB } \\
\end{array}$} & \multicolumn{2}{|c|}{$\begin{array}{l}\text { Participación en hs } \\
\text { exportaciones }\end{array}$} \\
\hline & 2012 & 2019 & 2012 & 2019 \\
\hline Petroleo y derivados & 11,966 & 4,968 & $54.8 \%$ & $43.1 \%$ \\
\hline Antioquia & 3,326 & 1,288 & $15.2 \%$ & $11.2 \%$ \\
\hline Bogotá & 1,088 & 802 & $5.0 \%$ & $7.0 \%$ \\
\hline Cundinamarca & 223 & 632 & $1.0 \%$ & $5.5 \%$ \\
\hline Bolinar & 844 & 467 & $3.9 \%$ & $4.1 \%$ \\
\hline Atlántico & 221 & 450 & $1.0 \%$ & $3.9 \%$ \\
\hline Valle de1Cauca & 411 & 424 & $1.9 \%$ & $3.7 \%$ \\
\hline Putumayo & 0 & 77 & $0.0 \%$ & $0.7 \%$ \\
\hline Caldas & 148 & 270 & $0.7 \%$ & $2.3 \%$ \\
\hline Santander & 212 & 297 & $1.0 \%$ & $2.6 \%$ \\
\hline Hulata & 448 & 201 & $2.1 \%$ & $1.7 \%$ \\
\hline Sucre & 1 & 300 & $0.0 \%$ & $2.6 \%$ \\
\hline Casanare & 987 & 208 & $4.5 \%$ & $1.8 \%$ \\
\hline Magdalena & 130 & 163 & $0.6 \%$ & $1.4 \%$ \\
\hline Cesar & 313 & 184 & $1.4 \%$ & $1.6 \%$ \\
\hline Meta & 370 & 353 & $1.7 \%$ & $3.1 \%$ \\
\hline Risaralda & 205 & 131 & $0.9 \%$ & $1.1 \%$ \\
\hline Quindio & 85 & 114 & $0.4 \%$ & $1.0 \%$ \\
\hline Cauca & 57 & 61 & $0.3 \%$ & $0.5 \%$ \\
\hline Boyacá & 0 & 2 & $0.0 \%$ & $0.0 \%$ \\
\hline Tolima & 290 & 40 & $1.3 \%$ & $0.3 \%$ \\
\hline Nariño & 11 & 25 & $0.1 \%$ & $0.2 \%$ \\
\hline Guajira & 163 & 19 & $0.7 \%$ & $0.2 \%$ \\
\hline Arauca & 287 & 34 & $1.3 \%$ & $0.3 \%$ \\
\hline Córdoba & 0 & 3 & $0.0 \%$ & $0.0 \%$ \\
\hline Norte de Santander & 41 & 7 & $0.2 \%$ & $0.1 \%$ \\
\hline San Andrés & 3 & 0 & $0.0 \%$ & $0.0 \%$ \\
\hline Chocó & 0 & 0 & $0.0 \%$ & $0.0 \%$ \\
\hline Caquetá & 0 & 0 & $0.0 \%$ & $0.0 \%$ \\
\hline Guainia & 0 & 0 & $0.0 \%$ & $0.0 \%$ \\
\hline Vaupés & 0 & 0 & $0.0 \%$ & $0.0 \%$ \\
\hline Vichada & 2 & 0 & $0.0 \%$ & $0.0 \%$ \\
\hline Total exp. & 21,833 & 11,520 & $100 \%$ & $100 \%$ \\
\hline
\end{tabular}

Fuente. Elaboración propia con datos del DANE. 
En la figura 3 se evidencia el cambio en la concentración de las exportaciones por departamento de origen, sin tener en cuenta «Petróleo y derivados», en el 2012 y el 2019. A pesar de que la concentración de las exportaciones no ha tenido mayor variación, se observa una mayor representación de Bogotá, Cundinamarca, Bolívar y Atlántico, caso contrario a Casanare. Así mismo, los departamentos de Putumayo y Caldas comienzan a involucrase un poco más en el comercio exterior con Estados Unidos, mientras que los departamentos de Amazonas, Guainía, Guaviare y Vaupés no registran datos de exportaciones durante los dos años.

Figura 3. Participación en las exportaciones de Colombia hacia Estados Unidos por departamento de origen — sin «Petróleo y derivados», CIF USD—

2012

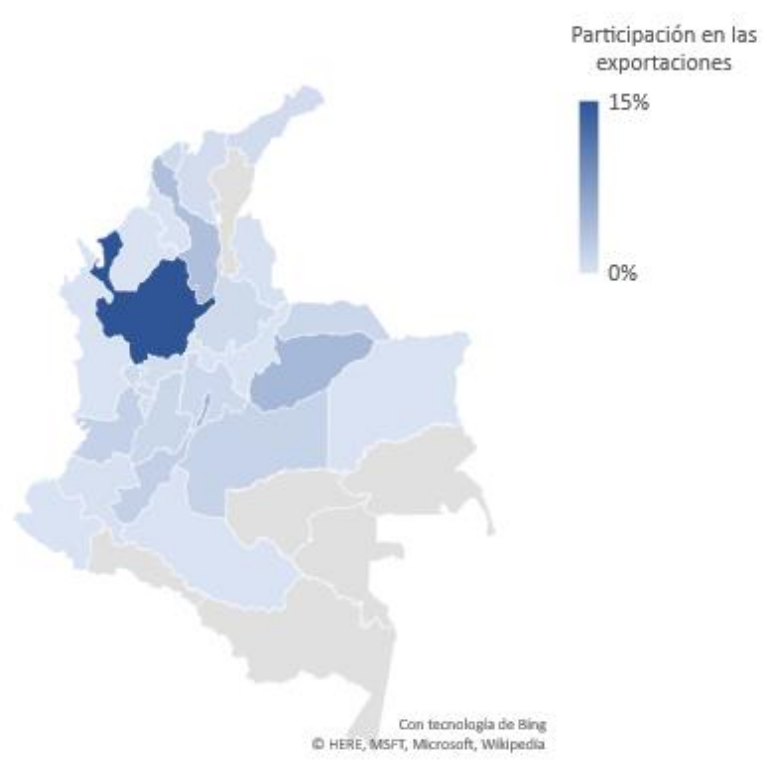

2019

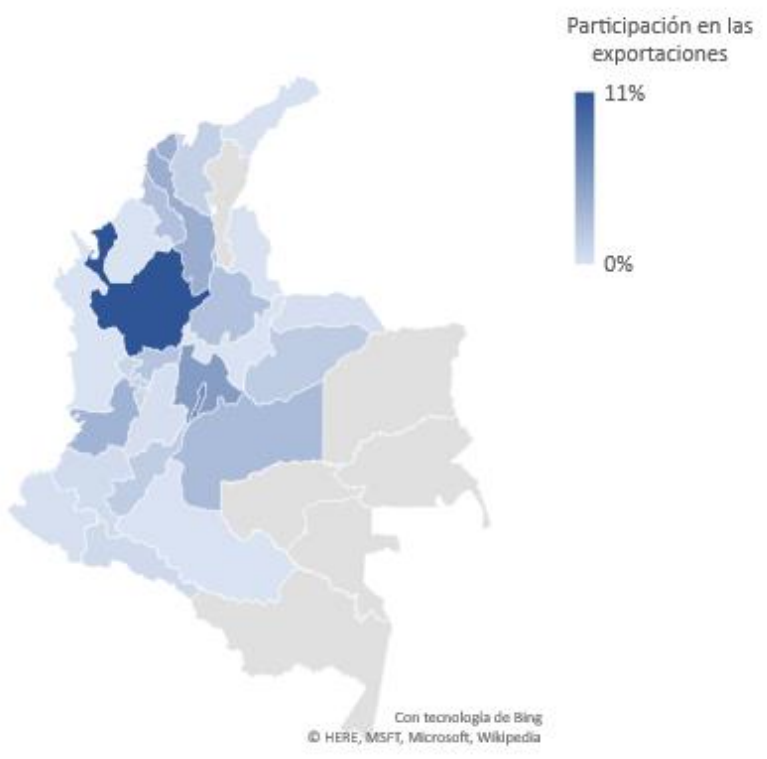

Fuente. Elaboración propia con datos del DANE. 
Para complementar el análisis de exportaciones a Estados Unidos, en la figura 4 se encuentran las posiciones arancelarias por principales ramas de actividad económica según su monto en dólares FOB que se exportaron a Estados Unidos en el 2012 y el 2019. Esto nos permite un acercamiento a la concentración de productos exportados y una percepción de la diversificación en la canasta exportadora que se tenía pensada en el momento de realizarse el tratado comercial.

Figura 4. Principales productos exportados a Estados Unidos según ramas de actividad económica -FOB USD-

2012

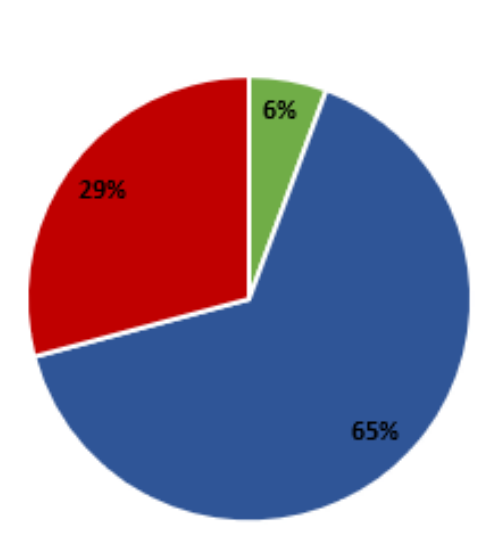

2019

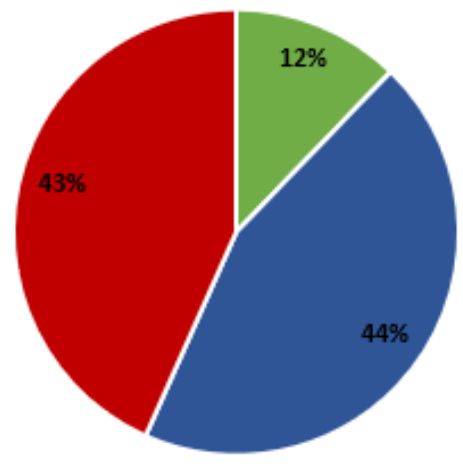

- Agricultura, pesca, ganadería, caza y silvicultura

- Explotación de Minas y Canteras

- Industria manufacturera

Fuente. Elaboración propia con datos del DANE.

Para el 2012, el 65,1\% de las exportaciones a Estados Unidos se concentró en la explotación de minas y cantera, pasando a 44 \% en el 2019. El sector manufacturero paso de representar el $29 \%$ al 43 \%, y el sector de agricultura, pesca, ganadería, caza y silvicultura duplicó su participación del $6 \%$ al 12 \%. Las demás actividades —artísticas, profesionales, información y telecomunicaciones, suministro de electricidad, gas y agua, transporte y almacenamiento, comercio y reparación de vehículos - tuvieron representación menor al $0,1 \%$. 
Los principales diez productos exportados por Colombia hacia Estados Unidos tuvieron una participación en el total de las exportaciones del 90 \% y el 77 \% en el 2012 y el 2019, respectivamente. Para el 2012 los principales cinco productos fueron aceites crudos de petróleo -62,8\%—, oro -12,2\%—, los demás cafés sin tostar -3,6\%—, combustibles fueloils -3,2\%- y un tipo de carbón mineral denominado hullas térmicas -2,3 \%-. Por su parte, para el 2019 se destacaron los aceites crudos de petróleo -42,5 \%—, los demás cafés sin tostar -8,4\%-, gasóleo -7,2 \%-, flores y capullos frescos -4,8 \%- y oro $4,1 \%$ -

A partir de los resultados, se observa que, a pesar de que en el transcurso del periodo de análisis hubo una disminución en la concentración de los productos exportados, el petróleo tiene aún una importante participación y los principales productos son similares, aunque varíe su representación. Adicionalmente, los sectores agrícola y manufacturero han aumentado su participación, pero no ocurre lo mismo con los demás sectores económicos.

Esta caracterización de las exportaciones colombianas refleja una vulnerabilidad de su sector externo, al estar exportando a su principal socio comercial, en su mayoría, productos expuestos a cambios en los precios internacionales. A partir del acuerdo comercial con Estados Unidos se puede inferir que Colombia no ha logrado una diversificación contundente hacia este mercado, lo que se refleja en retos frente a la competitividad del país y la resiliencia macroeconómica.

3.1.2. Importaciones de Colombia desde Estados Unidos — 2012 y 2019—.

El valor de las importaciones realizadas por el país en el 2012 se concentró, principalmente, en Bogotá, presentando una participación del 46,5 \%, seguido por los departamentos de Bolívar -15,1\%-, Antioquia -8,4\%-, Cundinamarca -7,1\%-, Atlántico -5,7 \%- y el restante 17,2 \% en los demás departamentos (véase la Tabla 3).

Para el 2019 se puede observar que Bogotá continúa en la posición de mayor participación, representando el 51,8 \% de las importaciones. En cuanto a los demás departamentos, Bolívar 
presentó una disminución del 5,4 \%, pasando a una participación de 9,7 \%; esta caída se vio compensada en el aumento de la participación de los departamentos de Antioquia, el cual creció en un 2,5\%, representando el 10,9\%, y Valle del Cauca pasando de un 4,7 \% en el 2012 a representar el 6,6 \% en el 2019.

Tabla 3. Importaciones de Colombia provenientes de Estados Unidos por departamento de destino

\begin{tabular}{|l|c|c|c|c|}
\hline \multirow{2}{*}{\begin{tabular}{c}
\multirow{2}{*}{ Departamento } \\
destino
\end{tabular}} & \multicolumn{2}{|c|}{$\begin{array}{c}\text { Millones USD } \\
\text { CIF }\end{array}$} & \multicolumn{2}{c|}{$\begin{array}{c}\text { Participación en las } \\
\text { importaciones }\end{array}$} \\
\cline { 2 - 5 } & $\mathbf{2 0 1 2}$ & $\mathbf{2 0 1 9}$ & $\mathbf{2 0 1 2}$ & $\mathbf{2 0 1 9}$ \\
\hline Bogotá & 6,594 & 6,875 & $46.5 \%$ & $51.8 \%$ \\
Antioquia & 1,197 & 1,452 & $8.4 \%$ & $10.9 \%$ \\
Bolívar & 2,141 & 1,285 & $15.1 \%$ & $9.7 \%$ \\
Valle del Cauca & 665 & 870 & $4.7 \%$ & $6.6 \%$ \\
Cundinamarca & 1,005 & 853 & $7.1 \%$ & $6.4 \%$ \\
Atlántico & 803 & 673 & $5.7 \%$ & $5.1 \%$ \\
Guajira & 537 & 319 & $3.8 \%$ & $2.4 \%$ \\
Santander & 168 & 284 & $1.2 \%$ & $2.1 \%$ \\
Cesar & 169 & 234 & $1.2 \%$ & $1.8 \%$ \\
Cauca & 86 & 95 & $0.6 \%$ & $0.7 \%$ \\
Magdalena & 213 & 84 & $1.5 \%$ & $0.6 \%$ \\
Risaralda & 55 & 54 & $0.4 \%$ & $0.4 \%$ \\
Petroleo y derivados & 0 & 33 & $0.0 \%$ & $0.2 \%$ \\
Norte de Santander & 57 & 27 & $0.4 \%$ & $0.2 \%$ \\
Quindio & 3 & 22 & $0.0 \%$ & $0.2 \%$ \\
Caldas & 27 & 21 & $0.2 \%$ & $0.2 \%$ \\
Córdoba & 27 & 19 & $0.2 \%$ & $0.1 \%$ \\
Casanare & 147 & 19 & $1.0 \%$ & $0.1 \%$ \\
Tolima & 15 & 19 & $0.1 \%$ & $0.1 \%$ \\
Boyacá & 30 & 11 & $0.2 \%$ & $0.1 \%$ \\
Meta & 213 & 8 & $1.5 \%$ & $0.1 \%$ \\
Nariño & 4 & 6 & $0.0 \%$ & $0.0 \%$ \\
Huila & 15 & 6 & $0.1 \%$ & $0.0 \%$ \\
Putumayo & 2 & 4 & $0.0 \%$ & $0.0 \%$ \\
Sucre & 3 & 2 & $0.0 \%$ & $0.0 \%$ \\
Chocó & 0 & 2 & $0.0 \%$ & $0.0 \%$ \\
Amazonas & 0 & 0 & $0.0 \%$ & $0.0 \%$ \\
Vichada & 0 & 0 & $0.0 \%$ & $0.0 \%$ \\
Arauca & 0 & 0 & $0.0 \%$ & $0.0 \%$ \\
Caquetá & 0 & 0 & $0.0 \%$ & $0.0 \%$ \\
San Andrés & 0 & 0 & $0.0 \%$ & $0.0 \%$ \\
Vaupés & & & & \\
Guainía & $0.0 \%$ & $0.0 \%$ \\
\hline Total imp. & $0.0 \%$ & $0.0 \%$ \\
\hline
\end{tabular}

Fuente. Elaboración propia con datos del DANE. 
En la figura 5 se evidencia el cambio en la concentración de las importaciones por departamento de destino, sin tener en cuenta «Petróleo y derivados», en el 2012 y el 2019. No se observan cambios importantes en la distribución departamental, manteniéndose los principales destinos; los departamentos del Cesar y Guaviare no tienen datos de importaciones en los dos años.

Figura 5. Participación en las importaciones de Colombia provenientes de Estados Unidos por departamento de destino — sin «Petróleo y derivados», CIF USD-

2012

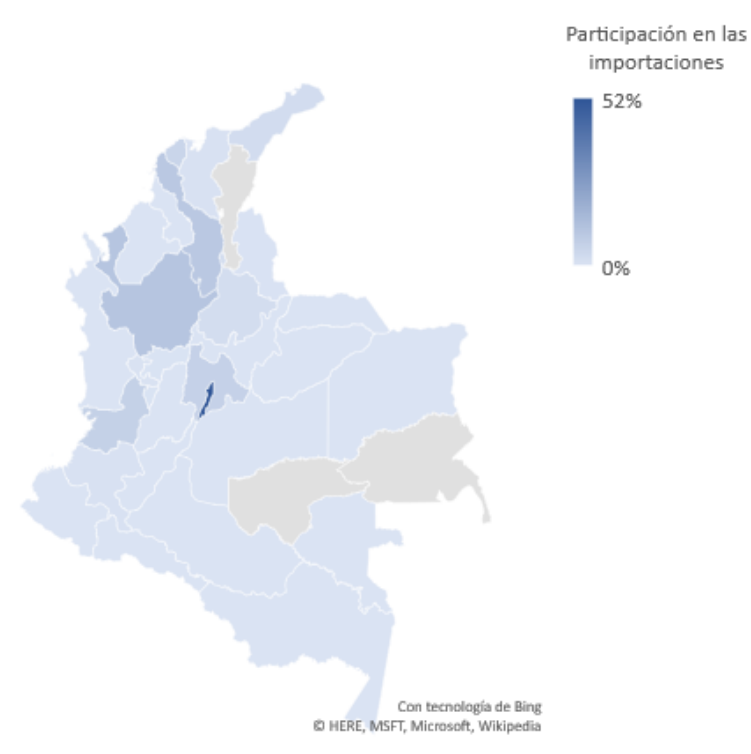

2019

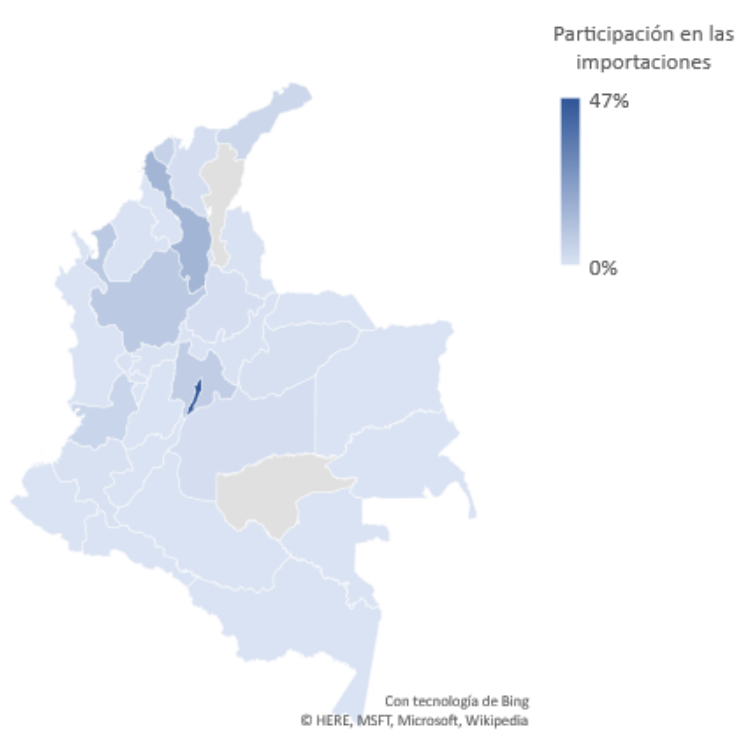

Fuente. Elaboración propia con datos del DANE.

Los productos importados por Colombia provenientes de Estados Unidos corresponden, principalmente, al sector manufacturero, con una participación de $96 \%$ en el 2012 y $89 \%$ en el 2019, seguido por el sector agrícola que aumentó su participación del 3,2 \% al $10 \%$ y explotación de minas y canteras que tuvo una representación del $1 \%$ en las importaciones desde Estados Unidos en el 2019 (Figura 6). Los demás sectores —actividades artísticas, actividades profesionales, información y telecomunicaciones, suministro de 
electricidad, gas y agua, transporte y almacenamiento- participaron en menos de 0,5\% durante los dos años.

Figura 6. Principales productos importados de Estados Unidos según ramas de actividad económica -CIF USD-

2012

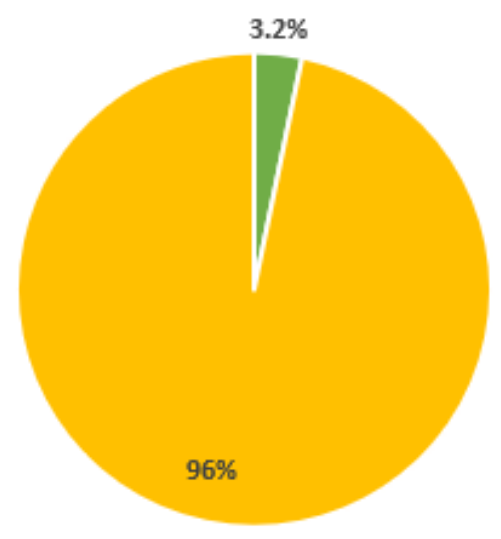

2019

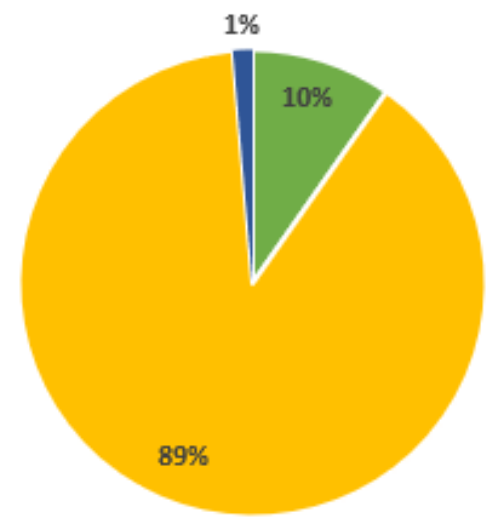

- Agricultura, pesca, ganadería, caza y silvicultura

- Industria manufacturera

- Explotación de Minas y Canteras

Fuente. Elaboración propia con datos del DANE.

Por posición arancelaria, los diez principales productos importados de Estados Unidos representaron el 32 \% de las importaciones totales, y para el 2019 tuvieron una participación del 38 \%. El producto con mayor participación fue gasóleo en los dos años, con una participación del 20 \% para el 2012 y 8 \% en el 2019. Otros principales productos para el 2012 fueron gasolinas sin tetraetilo de plomo - 2,8\%—, cloruro de vinilo - 1,6\%-, aceites livianos -1,3\%- y gasolinas sin tetraetilo de plomo - 1,3\%-. En el 2019, se importó aceites livianos -7,7\%—, gasolinas sin tetraetilo de plomo -5,3\%—, maíz amarillo $-5,1 \%-$, y tortas y demás residuos sólidos de la extracción de aceite de soja 3,3 \%-. Se refleja una menor concentración en comparación con las exportaciones, pero con una menor diversificación por sector económico. 


\subsection{Análisis del comercio exterior de Antioquia, Atlántico, Bogotá, Bolívar, Cundinamarca y Valle del Cauca con Estados Unidos}

En esta sección se presenta una caracterización comercial entre los departamentos más representativos en el comercio internacional entre Colombia y Estados Unidos. Los departamentos se definen a partir de la primera parte de resultados, tomando aquellos lugares de origen y destino que tienen una participación importante tanto en importaciones como en exportaciones en el 2012 y el 2019. Estos son: Antioquia, Atlántico, Bogotá, Bolívar, Cundinamarca y Valle del Cauca. El análisis de exportaciones se realiza excluyendo el lugar «Petróleo y derivados».

\subsubsection{Antioquia.}

El departamento de Antioquia se encuentra ubicado en el noroccidente del país, es el segundo con mayor participación en la economía colombiana representando el 14,5 \% del PIB nacional (DANE, 2018). En el comercio exterior participa con USD \$1 288 millones FOB - en las exportaciones y USD \$1 452 millones - CIF- en las importaciones (DANE, 2019). 
Tabla 4. Principales productos exportados hacia Estados Unidos por Antioquia —2012 y 2019—

\begin{tabular}{|c|c|c|c|}
\hline Producto & $\begin{array}{l}\text { Participación en las } \\
\text { exportaciones de } \\
\text { Antioquia (2012) }\end{array}$ & Producto & $\begin{array}{c}\text { Participación en las } \\
\text { exportaciones de } \\
\text { Antioquia (2019) }\end{array}$ \\
\hline $\begin{array}{l}\text { Oro(incluido el oro platinado), en las demás formas en } \\
\text { bruto, para uso no monetario. }\end{array}$ & $73 \%$ & $\begin{array}{l}\text { Oro(incluido el oro platinado), en las demás formas en } \\
\text { bruto, para uso no monetario. }\end{array}$ & $32 \%$ \\
\hline Bananas o plátanos frescos del tipo "cavendish valery" & $4 \%$ & Los demás cafés sin tostar, sin descafeinar. & $12 \%$ \\
\hline $\begin{array}{l}\text { Las demás flores y capullos frescos, cortados para ramos } \\
\text { o adornos. }\end{array}$ & $3 \%$ & Pompones frescos, cortados para ramos o adornos. & $6 \%$ \\
\hline Los demás cafés sin tostar, sin descafeinar. & $2 \%$ & $\begin{array}{c}\text { Las demás flores y capullos frescos, cortados para ramos } \\
\text { o adornos }\end{array}$ & $5 \%$ \\
\hline Pompones frescos, cortados para ramos o adornos. & $2 \%$ & Hortensias (Hydrangea spp) frescas & $4 \%$ \\
\hline Platino en bruto o en polvo. & $2 \%$ & $\begin{array}{l}\text { Las demás formas de oro semilabradas, para uso no } \\
\text { monetario. }\end{array}$ & $3 \%$ \\
\hline Los demás extractos, esencias y concentrados de café & $1 \%$ & $\begin{array}{c}\text { Pantalones largos, pantalones con peto, pantalones cortos } \\
\text { (calzones) y shorts, de tejidos llamados «mezclilla o } \\
\text { denim», para hombres o niños. }\end{array}$ & $3 \%$ \\
\hline $\begin{array}{c}\text { Pantalones largos, pantalones con peto, pantalones cortos } \\
\text { (calzones) y shorts, de tejidos llamados «mezclilla o } \\
\text { denim», para hombres o niños. }\end{array}$ & $1 \%$ & Café tostado, sin descafeinar, molido. & $3 \%$ \\
\hline Plátanos "plantains", frescos. & $1 \%$ & Plátanos "plantains", frescos. & $2 \%$ \\
\hline Café tostado, sin descafeinar, en grano. & $1 \%$ & Bananas o plátanos frescos del tipo "cavendish valery" & $2 \%$ \\
\hline
\end{tabular}

Fuente. Elaboración propia con datos del DANE.

Tabla 5. Principales productos importados desde Estados Unidos por Antioquia —2012 y 2019—

\begin{tabular}{|c|c|c|c|}
\hline Producto & $\begin{array}{l}\text { Participación en las } \\
\text { importaciones de } \\
\text { Antioquia (2012) }\end{array}$ & Producto & $\begin{array}{l}\text { Participación en las } \\
\text { importaciones de } \\
\text { Antioquia (2019) }\end{array}$ \\
\hline \begin{tabular}{|c} 
Algodón sin cardar ni peinar, de longitud de fibra superior \\
a $22.22 \mathrm{~mm}$ (7/8 pulgada) pero inferior o igual a 28.57 \\
$\mathrm{~mm}(11 / 8$ pulgada).
\end{tabular} & $5 \%$ & Maíz duro amarillo. & $16 \%$ \\
\hline Los demás trigos. & $3 \%$ & $\begin{array}{l}\text { Tortas y demás residuos sólidos de la extracción del } \\
\text { aceite de soja (soya), incluso molidos o en "pellets". }\end{array}$ & $11 \%$ \\
\hline Residuos de la industria del almidón y residuos similares. & $3 \%$ & $\begin{array}{l}\text { Las demás habas (porotos, frijoles, frejoles) de soja } \\
\text { (soya), incluso quebrantadas }\end{array}$ & $4 \%$ \\
\hline Turborreactores de empuje superior a 25 un. & $3 \%$ & Papel y cartón crudo, para caras (cubiertas) ("kraftliner"). & $2 \%$ \\
\hline $\begin{array}{l}\text { Tortas y demás residuos sólidos de la extracción del } \\
\text { aceite de soja (soya), incluso molidos o en "pellets". }\end{array}$ & $3 \%$ & Los demás trigos. & $2 \%$ \\
\hline $\begin{array}{l}\text { Las demás habas (porotos, frijoles, frejoles) de soja } \\
\text { (soya), incluso quebrantadas }\end{array}$ & $2 \%$ & Propulsores a reacción, excepto los turborreactores. & $2 \%$ \\
\hline $\begin{array}{l}\text { Heces y desperdicios de cervecería o de destilería, } \\
\text { incluso en "pellets" }\end{array}$ & $2 \%$ & $\begin{array}{l}\text { Pasta química de madera de coníferas, semiblanqueada o } \\
\text { blanqueada, a la sosa (soda) o al sulfato, excepto la pasta } \\
\text { para disolver. }\end{array}$ & $2 \%$ \\
\hline $\begin{array}{l}\text { Los demás papeles y cartones kraft, de gramaje superior } \\
\text { a } 150 \mathrm{~g} / \mathrm{m} 2 \text { pero inferior a } 225 \mathrm{~g} / \mathrm{m} 2 \text {. } \\
\end{array}$ & $2 \%$ & $\begin{array}{l}\text { Heces y desperdicios de cervecería o de destilería, } \\
\text { incluso en "pellets" }\end{array}$ & $2 \%$ \\
\hline Carbonato de disodio. & $2 \%$ & Carne deshuesada de la especie porcina, congelada & $2 \%$ \\
\hline Polietileno de densidad superior o igual a 0.94 . & $2 \%$ & $\begin{array}{c}\text { Los demás trozos y despojos de gallo o gallina, } \\
\text { congelados }\end{array}$ & $2 \%$ \\
\hline
\end{tabular}

Fuente. Elaboración propia con datos del DANE. 


\subsubsection{Atlántico.}

El departamento del Atlántico se encuentra ubicado en la región Caribe, representa el 4,4 \% de PIB colombiano (DANE, 2018) y participa en las importaciones y exportaciones totales con un valor de USD $\$ 450$ millones -FOB - y USD \$673 millones - CIF- (DANE, 2019).

Tabla 6. Principales productos exportados hacia Estados Unidos por Atlántico —-2012 y 2019—

\begin{tabular}{|c|c|c|c|}
\hline Producto & $\begin{array}{l}\text { Participación en las } \\
\text { exportaciones de } \\
\text { Atlántico (2012) }\end{array}$ & Producto & $\begin{array}{l}\text { Participación en las } \\
\text { exportaciones de } \\
\text { Atlántico (2019) } \\
\end{array}$ \\
\hline $\begin{array}{l}\text { Puertas, ventanas y sus marcos, bastidores y umbrales, de } \\
\text { aluminio. }\end{array}$ & $12 \%$ & $\begin{array}{l}\begin{array}{l}\text { Puertas, ventanas y sus marcos, bastidores y umbrales, de } \\
\text { aluminio. }\end{array} \\
\end{array}$ & $51 \%$ \\
\hline $\begin{array}{c}\text { Preparaciones y conservas de atunes, enteros o en trozos, } \\
\text { excepto picados. }\end{array}$ & $12 \%$ & $\begin{array}{l}\text { Ropa de tocador o de cocina, de tejido con bucles, de } \\
\text { tipo para toalla, de algodón. }\end{array}$ & $8 \%$ \\
\hline $\begin{array}{l}\text { Ropa de tocador o de cocina, de tejido con bucles, de } \\
\text { tipo para toalla, de algodón. }\end{array}$ & $11 \%$ & $\begin{array}{c}\text { Placas y hojas lisas de vidrio colado o laminado, sin } \\
\text { armar, coloreadas en la masa, opacificadas, chapadas o } \\
\text { con capa absorbente, reflectante o antirreflectante. }\end{array}$ & $7 \%$ \\
\hline $\begin{array}{c}\text { Placas y hojas lisas de vidrio colado o laminado, sin } \\
\text { armar, coloreadas en la masa, opacificadas, chapadas o } \\
\text { con capa absorbente, reflectante o antirreflectante. }\end{array}$ & $9 \%$ & $\begin{array}{c}\text { Los demás tapones, tapas, cápsulas y demás dispositivos } \\
\text { de cierre, de plástico. }\end{array}$ & $5 \%$ \\
\hline \begin{tabular}{|c|} 
Las demás materias del capítulo 96.02, exceptuando las \\
cápsulas de gelatina para envasar medicamentos.
\end{tabular} & $8 \%$ & Los demás perfiles de aleaciones de aluminio. & $4 \%$ \\
\hline $\begin{array}{l}\text { Los demás aceites pesados, excepto las que contengan } \\
\text { biodiesel y los desechos de aceites }\end{array}$ & $5 \%$ & $\begin{array}{l}\text { Los demás artículos de confitería sin cacao (incluido el } \\
\text { chocolate blanco). }\end{array}$ & $2 \%$ \\
\hline Aceites crudos de petróleo o de mineral bituminoso. & $4 \%$ & $\begin{array}{c}\text { Los demás medicamentos que contengan hormonas } \\
\text { corticosteroides, sus derivados y análogos estructurales } \\
\text { para uso humano, para uso humano. }\end{array}$ & $2 \%$ \\
\hline $\begin{array}{l}\text { Complementos alimenticios, que contengan } \\
\text { exclusivamente mezclas o extractos de plantas, partes de } \\
\text { plantas, semillas o frutos, con vitaminas, minerales u otras } \\
\text { sustancias. }\end{array}$ & $4 \%$ & $\begin{array}{c}\text { Desperdicios y desechos, de oro o de chapado (plaqué) } \\
\text { de oro, excepto las barreduras que contengan otro metal } \\
\text { precioso. }\end{array}$ & $1 \%$ \\
\hline Los demás fungicidas. & $4 \%$ & Acetatos de celulosa sin plastificar. & $1 \%$ \\
\hline Cápsulas de gelatina para envasar medicamentos. & $3 \%$ & $\begin{array}{c}\text { Preparaciones y conservas de atunes, enteros o en trozos, } \\
\text { excepto picados. }\end{array}$ & $1 \%$ \\
\hline
\end{tabular}

Fuente. Elaboración propia con datos del DANE. 
Tabla 7. Principales productos importados desde Estados Unidos por Atlántico — 2012 y 2019—

\begin{tabular}{|c|c|c|c|}
\hline Producto & $\begin{array}{l}\text { Participación en las } \\
\text { importaciones de } \\
\text { Atlántico (2012) } \\
\end{array}$ & Producto & $\begin{array}{l}\text { Participación en las } \\
\text { importaciones de } \\
\text { Atlántico (2019) } \\
\end{array}$ \\
\hline $\begin{array}{l}\text { Hidrogenoortofosfato de diamonio (fosfato } \\
\text { diamónico) }\end{array}$ & $6 \%$ & $\begin{array}{l}\text { Los demás arroces con cáscara (arroz } \\
\text { "paddy"). }\end{array}$ & $7 \%$ \\
\hline Los demás trigos. & $4 \%$ & $\begin{array}{c}\text { Hilados sencillos de fibras sin peinar con un } \\
\text { contenido de algodón, superior o igual a } 85 \% \\
\text { en peso. }\end{array}$ & $3 \%$ \\
\hline Ciclohexano. & $3 \%$ & Los demás trigos. & $3 \%$ \\
\hline $\begin{array}{l}\text { Dihidrogenoortofosfato de amonio } \\
\text { (fosfatomonoamónico), incluso mezclado con } \\
\text { el hidrogenoortofosfato de diamonio (fosfato } \\
\text { diamónico). }\end{array}$ & $3 \%$ & $\begin{array}{c}\text { Dihidrogenoortofosfato de amonio } \\
\text { (fosfatomonoamónico), incluso mezclado con } \\
\text { el hidrogenoortofosfato de diamonio (fosfato } \\
\text { diamónico). }\end{array}$ & $3 \%$ \\
\hline $\begin{array}{l}\text { Volquetes automotores concebidos para } \\
\text { utilizarlos fuera de la red de carreteras. }\end{array}$ & $2 \%$ & Maíz duro blanco. & $3 \%$ \\
\hline $\begin{array}{l}\text { Aceite de soja (soya) en bruto, incluso } \\
\text { desgomado. }\end{array}$ & $2 \%$ & $\begin{array}{l}\text { Hidrogenoortofosfato de diamonio (fosfato } \\
\text { diamónico) }\end{array}$ & $3 \%$ \\
\hline Aparatos de destilación o de rectificación. & $2 \%$ & $\begin{array}{c}\text { Las demás placas, láminas, hojas y tiras de } \\
\text { poli(vinilbutiral) para la fabricación de vidrios } \\
\text { de seguridad. }\end{array}$ & $2 \%$ \\
\hline Copolímeros de etileno con otras olefinas & $2 \%$ & $\begin{array}{c}\text { Carne deshuesada de la especie porcina, } \\
\text { congelada }\end{array}$ & $2 \%$ \\
\hline $\begin{array}{l}\text { Las demás partes identificables como } \\
\text { destinadas, exclusiva o principalmente a las } \\
\text { máquinas o aparatos de la partida } 84.25 \mathrm{a} \\
84.30 \text { no incluidos antes. }\end{array}$ & $1 \%$ & Maíz duro amarillo. & $2 \%$ \\
\hline $\begin{array}{l}\text { Polietileno de densidad superior o igual a } \\
0.94 .\end{array}$ & $1 \%$ & Disulfuro de carbono. & $2 \%$ \\
\hline
\end{tabular}

Fuente. Elaboración propia con datos del DANE.

\subsubsection{Bogotá.}

La capital de Colombia se ha consolidado como la primera economía del país desde 1960, manteniendo su participación a lo largo del tiempo y representando la cuarta parte de la economía con el 25,6 \% del PIB nacional para el 2018. En el 2019, las exportaciones fueron de USD 766 millones —FOB - y las importaciones de USD 6875 millones —CIF- (DANE, 2019). 
Tabla 8. Principales productos exportados hacia Estados Unidos por Bogotá —2012 y 2019—

\begin{tabular}{|c|c|c|c|}
\hline Producto & $\begin{array}{c}\text { Participación en las } \\
\text { exportaciones de } \\
\text { Bogotá (2012) } \\
\end{array}$ & Producto & \begin{tabular}{|c|} 
Participación en las \\
exportaciones de \\
Bogotá (2019) \\
\end{tabular} \\
\hline $\begin{array}{l}\text { Las demás flores y capullos frescos, cortados para ramos } \\
\text { o adornos. }\end{array}$ & $26 \%$ & Rosas frescas, cortadas para ramos o adornos. & $20 \%$ \\
\hline Rosas frescas, cortadas para ramos o adornos. & $20 \%$ & $\begin{array}{c}\text { Las demás flores y capullos frescos, cortados para ramos } \\
\text { o adornos }\end{array}$ & $18 \%$ \\
\hline Los demás cafés sin tostar, sin descafeinar. & $8 \%$ & Las demás partes de aviones o helicópteros & $7 \%$ \\
\hline $\begin{array}{l}\text { Los demás claveles frescos, cortados para ramos o } \\
\text { adornos. }\end{array}$ & $3 \%$ & $\begin{array}{l}\text { Las demás manufacturas de cuero natural o cuero } \\
\text { regenerado. }\end{array}$ & $4 \%$ \\
\hline $\begin{array}{l}\text { Los demás recipientes (bombonas (damajuanas), botellas, } \\
\text { frascos y artículos similares), de diferente capacidad }\end{array}$ & $3 \%$ & $\begin{array}{l}\text { Los demás claveles frescos, cortados para ramos o } \\
\text { adornos. }\end{array}$ & $3 \%$ \\
\hline $\begin{array}{l}\text { Las demás manufacturas de cuero natural o cuero } \\
\text { regenerado. }\end{array}$ & $3 \%$ & Alstroemerias frescas, cortadas para ramos o adornos. & $3 \%$ \\
\hline \begin{tabular}{|c|} 
Las demás placas, hojas, películas, bandas y láminas de \\
polímeros de cloruro de vinilo. \\
\end{tabular} & $2 \%$ & \begin{tabular}{|c|} 
Las demás placas, hojas, películas, bandas y láminas de \\
polímeros de cloruro de vinilo.
\end{tabular} & $2 \%$ \\
\hline Alstroemerias frescas, cortadas para ramos o adornos. & $2 \%$ & $\begin{array}{l}\text { Claveles miniatura frescos, cortados para ramos o } \\
\text { adornos. }\end{array}$ & $2 \%$ \\
\hline $\begin{array}{c}\text { Carburorreactores tipo gasolina, para reactores y } \\
\text { turbinas, excepto desechos de aceites y que contengan } \\
\text { biodiesel }\end{array}$ & $2 \%$ & Propulsores a reacción, excepto los turborreactores. & $2 \%$ \\
\hline $\begin{array}{c}\text { Teléfonos móviles (celulares) y los de otras redes } \\
\text { inalámbricas. }\end{array}$ & $1 \%$ & $\begin{array}{c}\text { Las demás plantas y partes de plantas, semillas y frutos de } \\
\text { las especies utilizadas principalmente en perfumería, en } \\
\text { medicina o como insecticidas, parasiticidas o similares, } \\
\text { frescos o secos, incluso cortados, quebrantados o } \\
\text { pulverizados. }\end{array}$ & $2 \%$ \\
\hline
\end{tabular}

Fuente. Elaboración propia con datos del DANE. 
Tabla 9. Principales productos importados desde Estados Unidos por Bogotá —2012 y 2019—

\begin{tabular}{|c|c|c|c|}
\hline Producto & $\begin{array}{c}\text { Participación en las } \\
\text { importaciones de } \\
\text { Bogotá (2012) } \\
\end{array}$ & Producto & $\begin{array}{l}\text { Participación en las } \\
\text { importaciones de } \\
\text { Bogotá (2019) } \\
\end{array}$ \\
\hline $\begin{array}{l}\text { Gasoils (gasóleo), excepto desechos de } \\
\text { aceites y que contengan biodiesel }\end{array}$ & $27 \%$ & $\begin{array}{c}\text { Los demás aceites livianos (ligeros) y sus } \\
\text { preparaciones, excepto desechos de aceites y } \\
\text { que contengan biodiesel }\end{array}$ & $15 \%$ \\
\hline $\begin{array}{l}\text { Aviones y demás aeronaves, de peso en } \\
\text { vacío, superior a } 15000 \mathrm{~kg} \text {. }\end{array}$ & $3 \%$ & $\begin{array}{l}\text { Gasoils (gasóleo), excepto desechos de } \\
\text { aceites y que contengan biodiesel }\end{array}$ & $15 \%$ \\
\hline $\begin{array}{c}\text { Los demás aceites livianos (ligeros) y sus } \\
\text { preparaciones, excepto desechos de aceites y } \\
\text { que contengan biodiesel }\end{array}$ & $2 \%$ & $\begin{array}{c}\text { Gasolinas sin tetraetilo de plomo, para } \\
\text { motores de vehículos automóviles, excepto } \\
\text { desechos de aceites y que contengan biodiesel }\end{array}$ & $10 \%$ \\
\hline Las demás partes de aviones o helicópteros & $2 \%$ & Maíz duro amarillo. & $2 \%$ \\
\hline $\begin{array}{c}\text { Gasolinas sin tetraetilo de plomo, para } \\
\text { motores de vehículos automóviles, excepto } \\
\text { desechos de aceites y que contengan biodiesel }\end{array}$ & $1 \%$ & $\begin{array}{l}\text { Aceites crudos de petróleo o de mineral } \\
\text { bituminoso. }\end{array}$ & $2 \%$ \\
\hline Los demás medicamentos para uso humano. & $1 \%$ & Los demás medicamentos para uso humano. & $2 \%$ \\
\hline $\begin{array}{l}\text { Las demás fracciones de la sangre y } \\
\text { productos inmunológicos, incluso modificados } \\
\text { u obtenidos por proceso biotecnológico, para } \\
\text { tratamiento oncológico o VIH. }\end{array}$ & $1 \%$ & $\begin{array}{l}\text { Las demás gasolinas sin tetraetilo de plomo, } \\
\text { excepto desechos de aceites y que contengan } \\
\text { biodiesel }\end{array}$ & $2 \%$ \\
\hline $\begin{array}{l}\text { Aparatos de telecomunicación por corriente } \\
\text { portadora o telecomunicación digital. }\end{array}$ & $1 \%$ & $\begin{array}{c}\text { Tortas y demás residuos sólidos de la } \\
\text { extracción del aceite de soja (soya), incluso } \\
\text { molidos o en "pellets". }\end{array}$ & $2 \%$ \\
\hline $\begin{array}{l}\text { Las demás partes identificables como } \\
\text { destinadas, exclusiva o principalmente a las } \\
\text { máquinas de sondeo o perforación de las } \\
\text { subpartidas Nros. } 84.30 .41 \text { u } 84.30 .49 \text {. }\end{array}$ & $1 \%$ & $\begin{array}{c}\text { Aviones y demás aeronaves, de peso en } \\
\text { vacío, superior a } 15000 \mathrm{~kg} \text {. }\end{array}$ & $1 \%$ \\
\hline $\begin{array}{l}\text { Partes de turborreactores o de } \\
\text { turbopropulsores. }\end{array}$ & $1 \%$ & \begin{tabular}{|} 
Camperos ( 4 x 4), para el transporte de \\
personas, con motor de émbolo (pistón) \\
alternativo, de encendido por chispa, de \\
cilindrada superior a $1.500 \mathrm{~cm} 3$ pero inferior \\
o igual a $3.000 \mathrm{~cm} 3$.
\end{tabular} & $1 \%$ \\
\hline
\end{tabular}

Fuente. Elaboración propia con datos del DANE.

\subsubsection{Bolívar.}

El departamento, ubicado en la región caribe, representa el 3,6 \% del PIB nacional (DANE, 2018). En el comercio exterior, según el DANE (2019), Bolívar participó en las importaciones nacionales con un valor de USD 1,285 millones - CIF- y en las exportaciones con un valor de USD 462 millones -FOB-. 
Tabla 10. Principales productos exportados hacia Estados Unidos por Bolívar — 2012 y 2019—

\begin{tabular}{|c|c|c|c|}
\hline Producto & $\begin{array}{c}\text { Participación en las } \\
\text { exportaciones de } \\
\text { Bolívar (2012) } \\
\end{array}$ & Producto & $\begin{array}{c}\text { Participación en las } \\
\text { exportaciones de } \\
\text { Bolívar (2019) } \\
\end{array}$ \\
\hline $\begin{array}{c}\text { Gasoils (gasóleo), excepto desechos de aceites y que } \\
\text { contengan biodiesel }\end{array}$ & $33 \%$ & Aceites crudos de petróleo o de mineral bituminoso. & $55 \%$ \\
\hline $\begin{array}{l}\text { Fueloils (fuel), excepto desechos de aceites y que } \\
\text { contengan biodiesel }\end{array}$ & $22 \%$ & $\begin{array}{l}\text { Codos, curvas y manguitos, roscados, de fundición, de } \\
\text { hierro o de acero. }\end{array}$ & $11 \%$ \\
\hline $\begin{array}{l}\text { Los demás aceites livianos (ligeros) y sus preparaciones, } \\
\text { excepto desechos de aceites y que contengan biodiesel }\end{array}$ & $13 \%$ & $\begin{array}{l}\text { Policloruro de vinilo, sin mezclar con otras sustancias, } \\
\text { obtenido por polimerización en emulsión. }\end{array}$ & $4 \%$ \\
\hline $\begin{array}{l}\text { Los demás tubos de entubación («casing») o de } \\
\text { producción («tubing»), de los tipos utilizados para la } \\
\text { extracción de petróleo o gas. }\end{array}$ & $10 \%$ & $\begin{array}{l}\text { Fueloils (fuel), excepto desechos de aceites y que } \\
\text { contengan biodiesel }\end{array}$ & $3 \%$ \\
\hline Aceites crudos de petróleo o de mineral bituminoso. & $10 \%$ & $\begin{array}{l}\text { Betunes y asfaltos naturales; asfaltitas y rocas asfálticas, } \\
\text { en estado natural y procesados. }\end{array}$ & $3 \%$ \\
\hline $\begin{array}{l}\text { Policloruro de vinilo, sin mezclar con otras sustancias, } \\
\text { obtenido por polimerización en emulsión. }\end{array}$ & $3 \%$ & Polipropileno. & $3 \%$ \\
\hline $\begin{array}{l}\text { Copolímeros de cloruro de vinilo y acetato de vinilo, sin } \\
\text { mezclar con otras sustancias. }\end{array}$ & $3 \%$ & Polieteres polioles derivados del oxido de propileno. & $2 \%$ \\
\hline $\begin{array}{l}\text { Las demás placas, láminas, hojas y tiras, de plástico no } \\
\text { celular y sin refuerzo, estratificación ni soporte o } \\
\text { combinación similar con otras materias, de polipropileno. }\end{array}$ & $1 \%$ & Tolueno. & $2 \%$ \\
\hline Amoniaco anhidro. & $1 \%$ & $\begin{array}{c}\text { Las demás placas, hojas, películas, bandas y láminas, de } \\
\text { plástico, obtenidas por estratificación con papel }\end{array}$ & $1 \%$ \\
\hline $\begin{array}{l}\text { Placas, láminas, hojas, y tiras de polímeros de cloruro de } \\
\text { vinilo con un contenido de plastificantes superior o igual al } \\
6 \% \text { en peso. }\end{array}$ & $1 \%$ & Copolímeros de propileno. & $1 \%$ \\
\hline
\end{tabular}

Fuente. Elaboración propia con datos del DANE.

Tabla 11. Principales productos importados desde Estados Unidos por Bolívar —2012 y 2019—

\begin{tabular}{|c|c|c|c|}
\hline Producto & $\begin{array}{l}\text { Participación en las } \\
\text { importaciones de } \\
\text { Bolívar (2012) } \\
\end{array}$ & Producto & \begin{tabular}{|c|} 
Participación en las \\
importaciones de \\
Bolívar (2019) \\
\end{tabular} \\
\hline $\begin{array}{l}\text { Gasoils (gasóleo), excepto desechos de aceites y que } \\
\text { contengan biodiesel }\end{array}$ & $37 \%$ & Cloruro de vinilo (cloroetileno). & $23 \%$ \\
\hline $\begin{array}{c}\text { Gasolinas sin tetraetilo de plomo, para motores de } \\
\text { vehículos automóviles, excepto desechos de aceites y que } \\
\text { contengan biodiesel }\end{array}$ & $12 \%$ & Propeno (propileno). & $21 \%$ \\
\hline Cloruro de vinilo (cloroetileno). & $11 \%$ & Estireno. & $9 \%$ \\
\hline Estireno. & $8 \%$ & $\begin{array}{l}\text { Aceites base para lubricantes excepto desechos de } \\
\text { aceites y que contengan biodiesel }\end{array}$ & $5 \%$ \\
\hline Propeno (propileno). & $7 \%$ & $\begin{array}{l}\text { Alcohol etilico y aguardiente desnaturalizados, de } \\
\text { cualquier graduación. }\end{array}$ & $5 \%$ \\
\hline $\begin{array}{l}\text { Aceites base para lubricantes excepto desechos de } \\
\text { aceites y que contengan biodiesel }\end{array}$ & $3 \%$ & Carne deshuesada de la especie porcina, congelada & $2 \%$ \\
\hline Metiloxirano (oxido de propileno). & $1 \%$ & $\begin{array}{c}\text { Dihidrogenoortofosfato de amonio } \\
\text { (fosfatomonoamónico), incluso mezclado con el } \\
\text { hidrogenoortofosfato de diamonio (fosfato diamónico). }\end{array}$ & $2 \%$ \\
\hline Polieteres polioles derivados del oxido de propileno. & $1 \%$ & Metiloxirano (oxido de propileno). & $2 \%$ \\
\hline Los demás remolcadores y barcos empujadores. & $1 \%$ & Gas natural licuado. & $2 \%$ \\
\hline $\begin{array}{c}\text { Dihidrogenoortofosfato de amonio } \\
\text { (fosfatomonoamónico), incluso mezclado con el } \\
\text { hidrogenoortofosfato de diamonio (fosfato diamónico). }\end{array}$ & $1 \%$ & Poli(metilenfenilisoclanato) (mdi bruto, mdi polimérico). & $1 \%$ \\
\hline
\end{tabular}

Fuente. Elaboración propia con datos del DANE. 


\subsubsection{Cundinamarca.}

El departamento de Cundinamarca, ubicado en el centro del país en la región Andina, ha representado un avance significativo en el comercio exterior: pasó de USD 426 millones -FOB - en el 2012, a USD 697 millones -FOB - en el 2019. En cuanto a las importaciones, para el 2019 tuvieron un valor de USD 853 de millones —CIF- (DANE, 2019).

Tabla 12. Principales productos exportados hacia Estados Unidos por Cundinamarca - 2012 y $2019-$

\begin{tabular}{|c|c|c|c|}
\hline Producto & $\begin{array}{l}\text { Participación en las } \\
\text { exportaciones de } \\
\text { Cundinamarca (2012) }\end{array}$ & Producto & $\begin{array}{l}\text { Participación en las } \\
\text { exportaciones de } \\
\text { Cundinamarca (2019) }\end{array}$ \\
\hline $\begin{array}{l}\text { Las demás flores y capullos frescos, cortados para ramos } \\
\text { o adornos. }\end{array}$ & $35 \%$ & $\begin{array}{l}\text { Las demás flores y capullos frescos, cortados para ramos } \\
\text { o adornos }\end{array}$ & $52 \%$ \\
\hline Rosas frescas, cortadas para ramos o adornos. & $21 \%$ & Rosas frescas, cortadas para ramos o adornos. & $14 \%$ \\
\hline $\begin{array}{l}\text { Los demás claveles frescos, cortados para ramos o } \\
\text { adornos. }\end{array}$ & $8 \%$ & $\begin{array}{l}\text { Los demás claveles frescos, cortados para ramos o } \\
\text { adornos. }\end{array}$ & $5 \%$ \\
\hline Alstroemerias frescas, cortadas para ramos o adornos. & $7 \%$ & Alstroemerias frescas, cortadas para ramos o adornos. & $4 \%$ \\
\hline $\begin{array}{c}\begin{array}{c}\text { Claveles miniatura frescos, cortados para ramos o } \\
\text { adornos. }\end{array} \\
\end{array}$ & $5 \%$ & $\begin{array}{l}\begin{array}{c}\text { Claveles miniatura frescos, cortados para ramos o } \\
\text { adornos. }\end{array} \\
\end{array}$ & $3 \%$ \\
\hline Aceites crudos de petróleo o de mineral bituminoso. & $5 \%$ & Los demás cafés sin tostar, sin descafeinar. & $3 \%$ \\
\hline $\begin{array}{l}\text { Las demás placas, hojas, películas, bandas y láminas de } \\
\text { polímeros de cloruro de vinilo. }\end{array}$ & $3 \%$ & $\begin{array}{c}\text { Las demás plantas y partes de plantas, semillas y frutos de } \\
\text { las especies utilizadas principalmente en perfumería, en } \\
\text { medicina o como insecticidas, parasiticidas o similares, } \\
\text { frescos o secos, incluso cortados, quebrantados o } \\
\text { pulverizados. } \\
\end{array}$ & $2 \%$ \\
\hline Pompones frescos, cortados para ramos o adornos. & $2 \%$ & \begin{tabular}{|c|} 
Las demás bombonas, (damajuanas), botellas, frascos, \\
bocales, tarros, envases tubulares y demás recipientes \\
para el transporte o envasado, de vidrio; bocales para \\
para conservas de vidrio, de capacidad superior a 0,331 \\
pero inferior o igual a 11. \\
\end{tabular} & $1 \%$ \\
\hline $\begin{array}{l}\text { Las demás manufacturas de cuero natural o cuero } \\
\text { regenerado. }\end{array}$ & $1 \%$ & Pompones frescos, cortados para ramos o adornos. & $1 \%$ \\
\hline $\begin{array}{l}\text { Las demás baldosas y losas, de cerámica para } \\
\text { pavimentación o revestimiento, barnizadas o esmaltadas. }\end{array}$ & $1 \%$ & $\begin{array}{c}\text { Transformadores de dieléctrico líquido de potencia } \\
\text { superior a } 10.000 \text { kva pero inferior o igual a } 110.000 \\
\text { kva. }\end{array}$ & $1 \%$ \\
\hline
\end{tabular}

Fuente. Elaboración propia con datos del DANE. 
Tabla 13. Principales productos importados desde Estados Unidos por Cundinamarca — 2012 y 2019

\begin{tabular}{|c|c|c|c|}
\hline Producto & $\begin{array}{c}\text { Participación en las } \\
\text { importaciones de } \\
\text { Cundinamarca (2012) }\end{array}$ & Producto & $\begin{array}{l}\text { Participación en las } \\
\text { importaciones de } \\
\text { Cundinamarca (2019) }\end{array}$ \\
\hline $\begin{array}{l}\text { Aceites base para lubricantes excepto desechos de } \\
\text { aceites y que contengan biodiesel }\end{array}$ & $3 \%$ & $\begin{array}{l}\text { Los demás productos inmunológicos dosificados o } \\
\text { acondicionados para la venta al por menor. }\end{array}$ & $7 \%$ \\
\hline Copolímeros de etileno con otras olefinas & $2 \%$ & $\begin{array}{l}\text { Policloruro de vinilo, sin mezclar con otras sustancias, } \\
\text { obtenido por polimerización en suspensión. }\end{array}$ & $4 \%$ \\
\hline Alcohol 2-etil-hexanol. & $2 \%$ & $\begin{array}{c}\text { Copolímeros de etileno y alfa-olefina de densidad inferior } \\
\text { a } 0,94\end{array}$ & $2 \%$ \\
\hline \begin{tabular}{|c|}
$\begin{array}{c}\text { Detergentes y dispersantes, incluso mezclados con otros } \\
\text { aditivos, que contengan aceites de petróleo o de mineral } \\
\text { bituminoso. }\end{array}$ \\
\end{tabular} & $2 \%$ & $\begin{array}{l}\text { Las demás habas (porotos, frijoles, frejoles) de soja } \\
\text { (soya), incluso quebrantadas }\end{array}$ & $2 \%$ \\
\hline $\begin{array}{c}\text { Las demás partes identificables como destinadas, } \\
\text { exclusiva o principalmente a las máquinas de sondeo o } \\
\text { perforación de las subpartidas Nros. } 84.30 .41 \mathrm{u} \\
84.30 .49 \text {. }\end{array}$ & $2 \%$ & $\begin{array}{l}\text { Leche y nata (crema) concentradas o con adición de } \\
\text { azúcar u otro edulcorante, en polvo, gránulos demás } \\
\text { formas sólidas, con un contenido de materias grasas } \\
\text { inferior o igual al } 1.5 \% \text { en peso. } \\
\end{array}$ & $2 \%$ \\
\hline $\begin{array}{l}\text { Los demás aviones y demás aeronaves, de peso en vacío, } \\
\text { superior a } 2000 \mathrm{~kg} \text { pero inferior o igual a } 15000 \mathrm{~kg} \text {. }\end{array}$ & $2 \%$ & Polietileno de densidad superior o igual a 0.94 . & $2 \%$ \\
\hline Polietileno de densidad superior o igual a 0.94 . & $2 \%$ & $\begin{array}{l}\text { Tortas y demás residuos sólidos de la extracción del } \\
\text { aceite de soja (soya), incluso molidos o en "pellets". }\end{array}$ & $2 \%$ \\
\hline $\begin{array}{l}\text { Preparaciones para fluidos de perforación de pozos } \\
\text { ("lodos"). }\end{array}$ & $1 \%$ & Polietileno de densidad inferior a 0.94 . & $2 \%$ \\
\hline $\begin{array}{c}\text { Poliacrilato de sodio cuya capacidad de absorción de una } \\
\text { solución acuosa de cloruro de sodio al } 1 \% \text {, sea superior o } \\
\text { igual a } 20 \text { veces su propio peso. }\end{array}$ & $1 \%$ & \begin{tabular}{|c|} 
Tapones y tapas ( incluidas las tapas roscadas y los \\
tapones vertedores ), cápsulas para botellas, tapones \\
roscados, sobretapas, precintos y demás accesorios para \\
envases, de metal común.
\end{tabular} & $2 \%$ \\
\hline $\begin{array}{l}\text { Los demás aditivos para aceites lubricantes que } \\
\text { contengan aceites de petróleo o de mineral bituminoso. }\end{array}$ & $1 \%$ & Residuos de la industria del almidón y residuos similares. & $2 \%$ \\
\hline
\end{tabular}

Fuente. Elaboración propia con datos del DANE.

\subsubsection{Valle del Cauca.}

El Valle del Cauca está ubicado en las regiones Andina y Pacífico, es la tercera economía que aporta al PIB nacional, con una participación del 9,7 \% en el 2018. En cuanto al comercio exterior, las exportaciones tuvieron un valor en el 2019 de USD 416 millones FOB - y las importaciones de USD 870 millones —CIF- (DANE, 2019). 
Tabla 14. Principales productos exportados hacia Estados Unidos por Valle del Cauca —2012 y 2019-

\begin{tabular}{|c|c|c|c|}
\hline Producto & $\begin{array}{l}\text { Participación en las } \\
\text { exportaciones de } \\
\text { V. del Cauca (2012) }\end{array}$ & Producto & $\begin{array}{l}\text { Participación en las } \\
\text { exportaciones de } \\
\text { V. del Cauca (2019) }\end{array}$ \\
\hline $\begin{array}{l}\text { Oro(incluido el oro platinado), en las demás formas en } \\
\text { bruto, para uso no monetario. }\end{array}$ & $53 \%$ & Los demás cafés sin tostar, sin descafeinar. & $19 \%$ \\
\hline $\begin{array}{c}\text { Los demás azúcares de caña en bruto, sin adición de } \\
\text { aromatizante ni colorante en estado sólido }\end{array}$ & $6 \%$ & $\begin{array}{l}\text { Oro(incluido el oro platinado), en las demás formas en } \\
\text { bruto, para uso no monetario. }\end{array}$ & $9 \%$ \\
\hline Bombones, caramelos, confites y pastillas. & $5 \%$ & $\begin{array}{c}\text { Los demás azúcares de caña o de remolacha y sacarosa } \\
\text { químicamente pura, en estado sólido. }\end{array}$ & $6 \%$ \\
\hline $\begin{array}{l}\text { Desperdicios y desechos, de oro o de chapado (plaqué) } \\
\text { de oro, excepto las barreduras que contengan otro metal } \\
\text { precioso. }\end{array}$ & $4 \%$ & $\begin{array}{c}\text { Neumáticos (llantas neumáticas) nuevos de caucho } \\
\text { radiales, de los tipos utilizados en autobuses o camiones. }\end{array}$ & $5 \%$ \\
\hline Los demás cafés sin tostar, sin descafeinar. & $4 \%$ & $\begin{array}{l}\text { Acumuladores eléctricos de plomo del tipo de los } \\
\text { utilizados para el arranque de los motores de explosión. }\end{array}$ & $5 \%$ \\
\hline Ácido cítrico. & $3 \%$ & $\begin{array}{l}\text { Los demás azúcares de caña en bruto, sin adición de } \\
\text { aromatizante ni colorante en estado sólido }\end{array}$ & $4 \%$ \\
\hline $\begin{array}{l}\text { Suéteres (jerseys), "pullovers", "cardigans", chalecos y } \\
\text { artículos similares, incluidos los "sous-pull", de punto, de } \\
\text { las demás fibras sintéticas. }\end{array}$ & $2 \%$ & Bombones, caramelos, confites y pastillas. & $4 \%$ \\
\hline $\begin{array}{l}\text { Bolsos de mano, incluso con bandolera o sin asas, con la } \\
\text { superficie exterior de cuero natural, de cuero regenerado } \\
\text { o cuero charolado. }\end{array}$ & $2 \%$ & $\begin{array}{c}\text { Los demás papeles y cartones sin fibras obtenidas por } \\
\text { procedimiento mecánico o químico-mecánico o con un } \\
\text { contenido total de estas fibras inferior o igual al } 10 \% \text { en } \\
\text { peso del contenido total de fibra, de peso superior o igual } \\
\text { a } 40 \mathrm{~g} / \mathrm{m} 2 \text { pero inferior o igual o igual a } 150 \mathrm{~g} / \mathrm{m} 2 \text {, en } \\
\text { hojas en las que un lado sea inferior o igual a } 435 \mathrm{~mm} \text { y el } \\
\text { otro sea inferior o igual a } 297 \mathrm{~mm} \text {, medido sin plegar. }\end{array}$ & $3 \%$ \\
\hline $\begin{array}{l}\text { Los demás azúcares de caña o de remolacha y sacarosa } \\
\text { químicamente pura, en estado sólido. }\end{array}$ & $2 \%$ & $\begin{array}{l}\begin{array}{c}\text { Desperdicios y desechos, de oro o de chapado (plaqué) } \\
\text { de oro, excepto las barreduras que contengan otro metal } \\
\text { precioso. }\end{array} \\
\end{array}$ & $2 \%$ \\
\hline $\begin{array}{l}\text { Limas, escofinas y herramientas similares de mano, de } \\
\text { metales comunes. }\end{array}$ & $1 \%$ & $\begin{array}{c}\text { Suéteres (jerseys), "pullovers", "cardigans", chalecos y } \\
\text { artículos similares, incluidos los "sous-pull", de punto, de } \\
\text { las demás fibras sintéticas. }\end{array}$ & $2 \%$ \\
\hline
\end{tabular}

Fuente. Elaboración propia con datos del DANE. 
Tabla 15. Principales productos importados desde Estados Unidos por Valle del Cauca —2012 y $2019-$

\begin{tabular}{|c|c|c|c|}
\hline Producto & $\begin{array}{c}\text { Participación en las } \\
\text { importaciones de } \\
\text { V. del Cauca (2012) }\end{array}$ & Producto & $\begin{array}{c}\text { Participación en las } \\
\text { importaciones de } \\
\text { V. del Cauca (2019) }\end{array}$ \\
\hline $\begin{array}{c}\text { Las demás habas (porotos, frijoles, frejoles) de soja } \\
\text { (soya), incluso quebrantadas }\end{array}$ & $4 \%$ & $21 \%$ & $9 \%$ \\
\hline Maíz duro amarillo. & $3 \%$ & $\begin{array}{c}\text { Tortas y demás residuos sólidos de la extracción del } \\
\text { aceite de soja (soya), incluso molidos o en "pellets". }\end{array}$ & $5 \%$ \\
\hline $\begin{array}{c}\text { Tortas y demás residuos sólidos de la extracción del } \\
\text { aceite de soja (soya), incluso molidos o en "pellets". }\end{array}$ & $2 \%$ & $\begin{array}{c}\text { Las demás habas (porotos, frijoles, frejoles) de soja } \\
\text { (soya), incluso quebrantadas }\end{array}$ & $4 \%$ \\
\hline $\begin{array}{c}\text { Las demás fracciones de la sangre y productos } \\
\text { inmunológicos, incluso modificados u obtenidos por } \\
\text { proceso biotecnológico. }\end{array}$ & $2 \%$ & Chuletas, costillas de la especie porcina congeladas & $2 \%$ \\
\hline $\begin{array}{c}\text { Los demás tractores (excepto carretillas - tractor de la } \\
\text { partida 87.09). }\end{array}$ & $2 \%$ & $\begin{array}{c}\text { Los demás vehículos para el transporte de personas, con } \\
\text { motor de émbolo (pistón) alternativo, de encendido por } \\
\text { chispa, de cilindrada superior a 1.500 cm3 pero inferior o } \\
\text { igual a 3.000 cm3. }\end{array}$ & $2 \%$ \\
\hline $\begin{array}{c}\text { Los demás componentes de la sangre humana, sueros } \\
\text { espećficos de animales y de personas, vacunas, toxinas y } \\
\text { productos similares para usos terapéuticos. }\end{array}$ & $2 \%$ & $\begin{array}{c}\text { Aceite de nabo (de nabina) o de colza con bajo contenido } \\
\text { de ácido erúcico y sus fracciones, en bruto, pero sin } \\
\text { modificar químicamente. }\end{array}$ & $2 \%$ \\
\hline Residuos de la industria del almidón y residuos similares. & $2 \%$ & Los demás trigos. & $2 \%$ \\
\hline Polietileno de densidad superior o igual a 0.94. & $2 \%$ & Alcohol propilico & $1 \%$ \\
\hline Hidrogenoortofosfato de diamonio (fosfato diamónico) & $2 \%$ & $\begin{array}{c}\text { Policloruro de vinilo, sin mezclar con otras sustancias, } \\
\text { obtenido por polimerización en suspensión. }\end{array}$ & $1 \%$ \\
\hline Manzanas frescas. & $\begin{array}{c}\text { Las demás mezclas de sustancias odoríferas y mezclas } \\
\text { incluidas las disoluciones alcohólicas) a base de una o } \\
\text { varias de estas sustancias, del tipo de las utilizadas como } \\
\text { materias básicas para la industria. }\end{array}$ & $1 \%$ \\
\hline
\end{tabular}

Fuente. Elaboración propia con datos del DANE.

\section{Conclusiones y recomendaciones}

El comercio exterior colombiano con su principal socio comercial tiene una importante representación en seis regiones, tanto para las exportaciones como para las importaciones. En las exportaciones se da una mayor concentración de Antioquia excluyendo a petróleo y derivados-, y para las importaciones la ciudad más importante en participación es Bogotá, entre el 2012 y el 2019.

Las exportaciones de petróleo tienen una importante representación durante el periodo de análisis, representando más del 40 \% de las exportaciones con destino a Estados Unidos. A pesar de que se observa una disminución de 12 puntos porcentuales de la participación entre el 2012 y el 2019, se mantiene como el principal producto de exportación. Por tanto, se evidencia la necesidad de impulsar la diversificación de la canasta 
exportadora, a fin de cumplir con el objetivo inicial del tratado y reducir la vulnerabilidad del sector externo de la economía.

En cuanto a las importaciones, los productos importados de Estados Unidos se caracterizan por ser de los sectores de mayor valor agregado, como, por ejemplo, el industrial. Además, entre el 2012 y el 2019 no se evidencia un cambio importante en los flujos comerciales.

Para futuras investigaciones se recomienda estudiar el comercio exterior de servicios, el cual presenta una gran oportunidad para la economía colombiana en materia de exportaciones y desarrollo económico. A su vez, un análisis más detallado de las principales regiones identificadas en este artículo es de utilidad en el propósito de contrastar los datos con el crecimiento económico departamental. Finalmente, se propone un mayor aprovechamiento de las bases de microdatos ofrecidas por el DANE que se usaron para la investigación, dado que puede brindar información relevante en cuanto a las empresas exportadoras e importadoras de cada región del país.

Este y otros estudios de comercio internacional permitirán identificar los patrones de comercio de Colombia, evaluar el impacto de los tratados de libre comercio que se han implementado y hacerles un seguimiento al cumplimiento de sus objetivos. De esta manera, se identifican los retos y las oportunidades existentes para contrarrestar el rezago de productividad y competitividad del país. 


\section{Referencias}

Bonilla-González, R. (2011). Apertura y reprimarización de la economía colombiana. Un paraíso de corto plazo. Revista Nueva Sociedad, (231), 46-65. Recuperado de https://bit.ly/33pNb9j

Casas, C., León, N.; Meléndez, M. (2005). Evaluación del impacto del TLC entre Colombia y Estados Unidos en la economía del Valle del Cauca. Fedesarrollo. Recuperado de https://bit.ly/3f2HfbJ

Departamento Administrativo Nacional de Estadística - DANE. (2018). PIB por departamento. Recuperado de https://bit.ly/3bbboo4

Departamento Administrativo Nacional de Estadística - DANE. (2019). Exportaciones. Recuperado de https://bit.ly/3nZPDgs

Ecopetrol. (2014). Coveñas: un puerto con historia. Recuperado de https://bit.ly/2QTzX29

Krugman, P.; Obstfeld, M. (2006). Economía internacional, Teoría y política. Madrid, España: Person.

Ladino, L.; Madrid, O. (2015). Análisis del TLC entre Colombia y Estados Unidos de América con los Estados de Colorado, Connecticut, Delaware, Dakota del Sur y Florida (trabajo de grado). Universidad del Rosario. Bogotá, Colombia. Recuperado de https://bit.ly/2Ryki8f

Martín, C.; Ramírez, J. M. (2004). El impacto económico de un acuerdo parcial de libre comercio entre Colombia y Estados Unidos. Banco de la República. DOI: https://doi.org/10.32468/be.326

Ministerio de Comercio, Industria y Turismo. (2018). Informe sobre los acuerdos comerciales vigentes en Colombia. Recuperado de https://bit.ly/3et2MLL

Ministerio de Comercio, Industria y Turismo. (2020). Informe sobre los acuerdos comerciales vigentes en Colombia. Recuperado de https://bit.ly/3bar2QS

Ministerio de Comercio, Industria y Turismo. (s. f.). Resumen del acuerdo entre Colombia y Estados Unidos. Recuperado de https://bit.ly/2RBqBIl

Moncayo-Jiménez, E. (2006). El TLC de Colombia con Estados Unidos y sus implicaciones en los departamentos. Revista Relaciones Internacionales, Estrategia y Seguridad, 1(1), 177-209: DOI: https://doi.org/10.18359/ries.208

Procolombia. (s. f.). ATPDEA. Recuperado de https://bit.ly/3xTjVG7 